\title{
Competing retention pathways of uranium upon reaction with $\mathrm{Fe}(\mathrm{II})$
}

Michael S. Massey ${ }^{\text {a,e,* }}$

Juan S. Lezama-Pacheco ${ }^{\text {a }}$

Morris E. Jones ${ }^{\text {a }}$

Eugene S. Ilton ${ }^{b}$

José M. Cerrato $^{\mathrm{c}}$

John R. Bargar ${ }^{\text {d }}$

Scott Fendorf ${ }^{a, *}$ 


\section{Abstract}

Biogeochemical retention processes, including adsorption, reductive precipitation, and incorporation into host minerals, are important in contaminant transport, remediation, and geologic deposition of uranium. Recent work has shown that $U$ can become incorporated into iron (hydr)oxide minerals, with a key pathway arising from $\mathrm{Fe}(\mathrm{II})$-induced transformation of ferrihydrite, $\left(\mathrm{Fe}(\mathrm{OH})_{3} \bullet n \mathrm{H}_{2} \mathrm{O}\right)$ to goethite $(\alpha-\mathrm{FeO}(\mathrm{OH}))$; this is a possible $\mathrm{U}$ retention mechanism in soils and sediments. Several key questions, however, remain unanswered regarding U incorporation into iron (hydr)oxides and this pathway's contribution to U retention, including: (i)

the competitiveness of $U$ incorporation versus reduction to $U(I V)$ and subsequent precipitation of $\mathrm{UO}_{2}$; (ii) the oxidation state of incorporated $\mathrm{U}$; (iii) the effects of uranyl aqueous speciation on $\mathrm{U}$ incorporation; and, (iv) the mechanism of $\mathrm{U}$ incorporation. Here we use a series of batch reactions conducted at $\mathrm{pH} \sim 7,[\mathrm{U}(\mathrm{VI})]$ from 1 to $170 \mu \mathrm{M},[\mathrm{Fe}(\mathrm{II})]$ from 0 to $3 \mathrm{mM}$, and [Ca] at 0 or $4 \mathrm{mM}$ ) coupled with spectroscopic examination of reaction products of $\mathrm{Fe}(\mathrm{II})$-induced ferrihydrite transformation to address these outstanding questions. Uranium retention pathways were identified and quantified using extended X-ray absorption fine structure (EXAFS) spectroscopy, X-ray powder diffraction, X-ray photoelectron spectroscopy, and transmission electron microscopy. Analysis of EXAFS spectra showed that 14 to $89 \%$ of total U was incorporated into goethite, upon reaction with $\mathrm{Fe}(\mathrm{II})$ and ferrihydrite. Uranium incorporation was a particularly dominant retention pathway at $\mathrm{U}$ concentrations $\leq 50 \mu \mathrm{M}$ when either uranylcarbonato or calcium-uranyl-carbonato complexes were dominant, accounting for 64 to $89 \%$ of total U. With increasing U(VI) and Fe(II) concentrations, U(VI) reduction to U(IV) became more prevalent, but $\mathrm{U}$ incorporation remained a functioning retention pathway. These findings highlight the potential importance of $\mathrm{U}(\mathrm{V})$ incorporation within iron oxides as a retention 
60 process of $U$ across a wide range of biogeochemical environments and the sensitivity of uranium

61 retention processes to operative (bio)geochemical conditions.

\section{1. Introduction}

Uranium mining, milling, refining, and nuclear weapons production in the United States

64 has left a legacy of soil and groundwater contamination at a variety of sites such as Hanford, WA

65 and Oak Ridge, TN. The United States Department of Energy manages an inventory of 1.5

66 billion $\mathrm{m}^{3}$ of contaminated groundwater, and 75 million $\mathrm{m}^{3}$ of contaminated soil/sediment (DOE,

67 1997); $\mathrm{U}$ is among the most common radionuclide contaminants at DOE sites (Riley and

68 Zachara, 1992). Uranium contamination from legacy U production exists on every continent

69 except Antarctica, with an estimated global volume of over 900 million $\mathrm{m}^{3}$ of tailings, covering

70 nearly 6,000 ha, with associated contamination of soils, sediments, and groundwater (IAEA,

71 2004). Managing this legacy $U$ contamination requires an accurate understanding of $U$

72 biogeochemical processes and sequestration mechanisms. Uranium biogeochemistry also plays

73 key roles in $\mathrm{U}$ extraction/mining, $\mathrm{U}$ contamination remediation, and environmental fate and

74 transport of $U$. Thus, establishing a clearer understanding of $U$ biogeochemistry is crucial for

75 mitigating the impact of legacy contamination, as well as understanding current and future

76 environmental impacts of $U$.

In the subsurface environment, $U$ retention processes remove $U$ from the groundwater in which it is transported, concentrating it in potentially economically extractable quantities (e.g., in

79 roll-front deposits), and alleviating U toxicity risks in groundwater. Uranium sequestration

80 mechanisms are heavily influenced by U oxidation state: U(VI) is the most mobile form in the

81 environment and exists as the uranyl cation, $\mathrm{UO}_{2}{ }^{2+}$, and associated species, while $\mathrm{U}(\mathrm{IV})$ tends to 
form sparingly-soluble precipitates such as uraninite $\left(\mathrm{UO}_{2(s)}\right)$. Recent theoretical studies

83 (Skomurski et al., 2011; Wander and Shuford, 2012) and laboratory work (Ilton et al., 2005; Ilton

et al., 2010; Ilton et al., 2012) suggest that U(V) might also be environmentally relevant. However, field-based evidence for $\mathrm{U}(\mathrm{V})$ is rare, with only one $\mathrm{U}(\mathrm{V})$ mineral (wyarite), having been identified (Burns and Finch, 1999). There are four primary U retention pathways: adsorption of $\mathrm{U}(\mathrm{VI})$, precipitation of $\mathrm{U}(\mathrm{VI})$ minerals such as uranyl silicates (Catalano and Brown, 2004; Burns, 2005) or phosphates (Stubbs et al., 2009), reductive precipitation of U(IV) (Lovley and Phillips, 1992b; Liger et al., 1999; Du et al., 2011; Latta et al., 2012b), and, incorporation/co-precipitation of $\mathrm{U}$ in host minerals such as iron oxides (collectively used here to refer to hydroxides, oxyhydroxides, and oxides) (Payne et al., 1994; Duff et al., 2002; Nico et al., 2009; Stewart et al., 2009; Ilton et al., 2010; Boland et al., 2011; Ilton et al., 2012; Marshall et al., 2014), or silicates (Allard et al., 1999; Soderholm et al., 2008).

Uranyl adsorption is dependent on $\mathrm{pH}, \mathrm{U}$ aqueous speciation, and mineralogical constituents. Waite et al. (1994) found nearly complete uranyl adsorption on ferrihydrite at circumneutral $\mathrm{pH}$. Aqueous uranyl-carbonato and uranyl-calcium-carbonato ternary complexes also decrease the extent of $U$ adsorption (Stewart et al., 2010). However, adsorption does occur in the presence of uranyl-carbonato and uranyl-calcium-carbonato complexes as an inner-sphere uranyl-carbonato (Bargar et al., 1999) or uranyl surface complex (Rossberg et al., 2009; Hiemstra et al., 2009). Uranium adsorption is fast but ultimately reversible, thus operating as a primarily short-term retention mechanism.

Uranium in the hexavalent oxidation state also forms minerals such as uranyl hydroxides (e.g., schoepite and metaschoepite), uranyl silicates (e.g., uranophane), uranyl carbonates (e.g., liebigite), and uranyl phosphates (e.g., autunite, torbernite and metatorbernite) (Finch and 
Murakami, 1999; Burns, 2005). Uranyl minerals are a potential sink for U and have been found at contaminated sites (Catalano et al., 2004; Wang et al., 2005; Stubbs et al., 2009). Precipitation of uranyl minerals may be important for $\mathrm{U}$ retention in oxygenated environments such as arid or semi-arid soils and sediments, if the minerals limit $U$ migration and mitigate toxic impacts.

Reductive precipitation of $\mathrm{U}$ as $\mathrm{U}(\mathrm{IV})$ has also been extensively studied, chiefly as an in situ remediation technique (Lovley and Phillips, 1992b; Anderson et al., 2003; Wu et al., 2006; Neiss et al., 2007; Yabusaki et al., 2007). Uranium is retained as sparingly-soluble uraninite (e.g., Suzuki et al., 2002), or as "monomeric" or "mononuclear" U(IV) (e.g., Bernier-Latmani et al., 2010; Boyanov et al., 2011). Uranium reduction can occur via biotic or abiotic processes. Abiotically, $\mathrm{U}$ reduction is facilitated by reaction with $\mathrm{Fe}(\mathrm{II})$, which can be catalyzed by mineral surfaces (Liger et al., 1999; Chakraborty et al., 2010; Latta, et al., 2012a). Heterogeneous U reduction by reduced minerals such as Fe sulfides and magnetite is also possible (Hua and Deng, 2008; Latta, Gorski, et al., 2012; Hyun et al., 2012; Singer et al., 2012), as is homogeneous U reduction by aqueous Fe(II) (Du et al., 2011) or sulfide (Hua et al., 2006). Biotically, various dissimilatory metal reducing bacteria can use U for respiration (Lovley and Phillips, 1992b; Wilkins et al., 2006), while others reduce U via a non-respiratory pathway (Lovley and Phillips, 1992a). However, the rate and extent of $U$ reduction is diminished by uranyl-calcium-carbonato complexes (Brooks et al., 2003; Neiss et al., 2007; Boyanov et al., 2007; Sheng et al., 2011; Singer et al., 2012), with inhibition occurring due to kinetic rather than thermodynamic factors (Stewart et al., 2007).

Uranium may also be retained through incorporation within the structure of other host minerals. For example, Pett-Ridge et al. (2007) concluded that non-exchangeable U in 150 to 4100 ka Hawaiian soils was co-precipitated with Fe to form iron oxides, and Sato et al. (1997) 
128 showed that iron oxides scavenged greater than $8 \% \mathrm{U}$ (by weight) from waters down gradient of 129 the Koongarra deposit in Australia. Because of a spatial correlation among U, Cu, and P, Sato et 130 al. (1997) postulated that $\mathrm{U}$ was present in both a torbernite/metatorbernite $\left(\mathrm{Cu}\left(\mathrm{UO}_{2}\right)_{2}\left(\mathrm{PO}_{4}\right)_{2} \bullet 8\right.$ $131 \quad 12 \mathrm{H}_{2} \mathrm{O}$ ) phase and a goethite phase. Payne et al. (2006) postulated an adsorption step followed 132 by solid phase incorporation during mineral ripening to more crystalline phases.

While the above examples demonstrate the importance of co-precipitation on geologic 134 time scales, this process is also active on much shorter time scales of days to decades. For 135 example, at the United States Department of Energy's Oak Ridge site, Stubbs et al. (2006) 136 identified not only distinct uranyl phosphate phases but also goethite-associated $\mathrm{U}$ as phases 137 controlling the aqueous concentration of U. In addition, Gomez et al. (2006) concluded that U 138 co-precipitation with iron oxides controlled the release of $U$ from an abandoned $U$ mine in Spain. 139 Senko et al. (2005) also noted that addition of $\mathrm{Fe}(\mathrm{II})$ during oxidation of authigenic $\mathrm{UO}_{2}$-bearing 140 solids resulted in diminished release of aqueous U(VI), which is consistent with U(VI/V) 141 incorporation into transforming/precipitating Fe(III) oxides. Gu et al. (2003) also postulated, on 142 the basis of uptake and extraction data, that $\mathrm{U}$ co-precipitation with Fe and/or $\mathrm{Al}$ oxides had a 143 significant influence on dissolved concentrations of $\mathrm{U}$.

144 Uranium incorporation has been demonstrated in hematite (Duff et al., 2002; Ilton et al., 145 2012; Marshall et al., 2014) after heating and aging of U and Fe co-precipitates. Payne et al. 146 (1994) also found that $\mathrm{U}$ adsorbed on ferrihydrite became resistant to extraction after heating and 147 aging transformed the ferrihydrite to hematite and lesser amounts of goethite. Uranium 148 incorporation into octahedral Fe(III) sites in goethite has been posited (Nico et al., 2009; Boland 149 et al., 2011), and U incorporation into magnetite has also been proposed (Nico et al., 2009). In all 150 experiments, $\mathrm{U}$ that had purportedly incorporated into iron oxides was resistant to extraction and 
151 re-mobilization (Duff et al., 2002; Stewart et al., 2009; Smith et al., 2009; Ilton et al., 2012).

152 Whether by heating or Fe(II)-induced transformation, the incorporation of U into iron oxides can

153 occur in days to weeks (Nico et al., 2009; Boland et al., 2011). Iron(II)-induced transformation of

154 ferrihydrite to goethite occurs as a coupled dissolution-reprecipitation process (Hansel et al.,

155 2003) and $U$ is incorporated into the goethite lattice during the transformation. Since U

156 incorporation can result in $\mathrm{U}$ that is resistant to re-mobilization (Stewart et al., 2009), U

157 incorporation into transforming iron oxides can strongly retain $\mathrm{U}$, potentially over long periods

158 of time.

159 Kerisit et al. (2011) conducted atomistic modeling of U incorporated in the structure of

160 various iron oxides. The simulated local structures around U(V) or U(VI) in Fe(III) sites yielded

161 a good match with the EXAFS data reported by Nico et al. (2009). Charge balance was

162 maintained by protonation/de-protonation of neighboring hydroxyl groups and/or the

163 introduction of vacancies at other Fe(III) sites. The combination of modeling and experimental

164 approaches provide strong evidence for $\mathrm{U}(\mathrm{V} / \mathrm{VI})$ incorporation into the structure of goethite

165 during reductive transformation of ferrihydrite. However, important aspects of the U

166 incorporation mechanism and resulting solid-phase product(s) remain unresolved. The objective

167 of the present work was therefore to address several knowledge gaps, including: (1) the

168 relevance of $\mathrm{U}$ incorporation at commonly-observed concentrations of calcium, carbonate, $\mathrm{U}$,

169 and Fe; (2) the mechanisms by which $\mathrm{U}$ is incorporated, including the valence state of

170 incorporated $\mathrm{U}$; and, (3) competition between $\mathrm{U}$ incorporation, reduction, and adsorption

171 processes. 


\section{2. Methods}

173 2.1. Sample preparation and solution chemical analyses

\section{$174 \quad$ 2.1.1. Two-line ferrihydrite preparation}

Two-line ferrihydrite slurry was prepared according to the method outlined in Herbel and

176 Fendorf (2006). Briefly, $150 \mathrm{mM}$ ferric chloride was vigorously mixed using a mechanical

177 stirrer, and rapidly (within $\sim 15$ minutes) titrated to a $\mathrm{pH}$ of 7.0-7.5 using 0.4-1 M sodium

178 hydroxide. After 1-2 hours of equilibration and further addition of sodium hydroxide to establish

179 a stable $\mathrm{pH}$ in the 7.0-7.5 range, the slurry was allowed to settle, and the supernatant was

180 decanted. The slurry was then centrifuged and washed with de-ionized water (18 M $\Omega$ ) five times

181 to remove residual salts. Two-line ferrihydrite mineralogy was confirmed using high-resolution

182 synchrotron X-ray powder diffraction at beamline 7-2 at the Stanford Synchrotron Radiation

183 Lightsource (SSRL). Slurry density was measured by the ferrozine assay (Stookey, 1970)

184 following dissolution of ferrihydrite in $6 \mathrm{M}$ hydrochloric acid and complete reduction of Fe(III) 185 to Fe(II) using 0.5 M hydroxylamine hydrochloride.

In order to compare the present study with previous experiments (e.g., Nico et al., 2009),

187 ferrihydrite-coated sand was also prepared using the method described by Brooks et al. (1996).

188 Ferrihydrite slurry was prepared as above, and mixed with pure quartz sand (Unimin

189 Corporation, New Canaan, Connecticut, United States).

\subsubsection{Variable U(VI) incubations}

Ferrihydrite slurry was incubated with $300 \mu \mathrm{M} F($ II) and 1-170 $\mu \mathrm{M}$ uranyl to determine

192 the distribution of $\mathrm{U}$ retention pathways across a range of initial U(VI) concentrations. Batch 
193 incubations were performed in $125 \mathrm{~mL}$ glass serum vials with thick rubber septum stoppers

194 (Bellco Glass, Inc., New Jersey, United States). Two sample series were prepared: a no-Ca

195 series, and a series with $4 \mathrm{mM} \mathrm{Ca}$. A solution with a final concentrations of $10 \mathrm{mM}$ piperazine-

196 N,N'-bis(2-ethansulfonic acid) (PIPES) buffer, $3.8 \mathrm{mM} \mathrm{KHCO}_{3}$, and 0 or $4 \mathrm{mM} \mathrm{CaCl}_{2}$, adjusted

197 to $\mathrm{pH} 7.0$, served as the aqueous reaction medium. Ferrihydrite slurry $\left(1.7 \times 10^{-4} \mathrm{~mol} \mathrm{Fe} \mathrm{bottle}{ }^{-1}\right)$

198 and varying concentrations of uranyl acetate $(0,1,3,5,10,50,100,170 \mu \mathrm{M})$ were added to each

199 reaction vessel. Ferrihydrite-coated sand samples were prepared with $1 \mathrm{~g}$ of ferrihydrite-coated

200 sand (also approximately $1.7 \times 10^{-4} \mathrm{~mol} \mathrm{Fe} \mathrm{bottle}^{-1}$, as in the slurry experiments) rather than

201 ferrihydrite slurry. The ferrihydrite-coated sand experiment used the same aqueous reaction

202 medium, with $4 \mathrm{mM} \mathrm{Ca}$, and $170 \mu \mathrm{M} \mathrm{U}$. Then the mixture in each vessel was allowed to

203 equilibrate for $\sim 1 \mathrm{~h}$, and spiked with $300 \mu \mathrm{M}$ Fe(II) (added as $\mathrm{FeSO}_{4}$ ). The total solution volume

204 in all cases was $100 \mathrm{~mL}$. A no-Fe(II), no-Ca, $50 \mu \mathrm{M}$ U sample was also made as a standard for

205 uranyl adsorption on ferrihydrite. An incubation where $50 \mu \mathrm{M} \mathrm{U}$ was added after ferrihydrite

206 transformation was also performed, to evaluate the ability for $\mathrm{U}$ to be incorporated into goethite

207 after transformation. The entire procedure was performed using de-oxygenated, de-ionized (18

$208 \mathrm{M} \Omega$ ) water in an anoxic $\left(95 \% \mathrm{~N}_{2}, 5 \% \mathrm{H}_{2}\right)$ atmosphere (Coy Laboratory Products Inc., Michigan,

209 United States).

210 Samples were incubated outside of the anaerobic glovebag at $25^{\circ} \mathrm{C}$ for $8-10$ days on a

211 rotary shaker at $120 \mathrm{RPM}$. After incubation, $10 \mathrm{~mL}$ aliquots of solution were withdrawn using a

212 syringe, and filtered through $0.22 \mu \mathrm{m}$ membranes into $25 \mathrm{~mL}$ serum vials. Serum vials were then

213 capped with rubber septum stoppers and stored at $4^{\circ} \mathrm{C}$ until analysis. The remaining

214 solution/slurry mixture was vacuum filtered onto a $0.22 \mu \mathrm{m}$ pore membrane filter (Millipore,

215 Inc., Massachusetts, United States) and rinsed with de-ionized water. While still wet, samples 
were scraped from the filters and allowed to dry prior to grinding and analysis. All sample

217 harvesting and processing was performed in an anoxic atmosphere, as above. This process

218 yielded $\sim 15-20 \mathrm{mg}$ of dried iron oxide powder per $125 \mathrm{~mL}$ serum vial. Between 3-6 replicates of

219 each incubation were performed in separate bottles, and combined to ensure sufficient mass of

220 sample for analysis. Iron-coated sand samples were not ground and were simply dried for 221 analysis.

\subsubsection{Variable $\mathrm{Fe}(\mathrm{II})$ incubations}

Constant-U, variable-Fe(II) incubations were also performed to evaluate the effect of

$224 \mathrm{Fe}(\mathrm{II})$ on $\mathrm{U}$ incorporation and $\mathrm{U}$ reduction to $\mathrm{U}(\mathrm{IV})$. As in the variable-U incubations described

225 above, the solutions had a final reaction volume of $100 \mathrm{~mL}$ per $125 \mathrm{~mL}$ serum bottle, and all

226 incubations were conducted in an anoxic atmosphere. The solutions consisted of $10 \mathrm{mM}$ PIPES

227 buffer, $3.8 \mathrm{mM}$ sodium bicarbonate, either 0 or $4 \mathrm{mM} \mathrm{CaCl}_{2}$, and $127 \mathrm{uM}$ uranyl acetate. Two-

228 line ferrihydrite slurry was added to a final density of $1.7 \times 10^{-4}$ mol Fe bottle ${ }^{-1}$. Bottles were

229 sealed and allowed to equilibrate for $\sim 1$ hour, after which Fe(II) was added by syringe to

230 concentrations ranging from 0 to $3 \mathrm{mM}\left(0,0.3\right.$, 1 , and $3 \mathrm{~mL}$ of $\left.100 \mathrm{mM} \mathrm{FeSO}_{4}\right)$. Bottles were

231 shaken at $120 \mathrm{RPM}$ at $25^{\circ} \mathrm{C}$ for 10 days outside of the anaerobic chamber.

After 10 days the bottles were returned to the anaerobic chamber for sampling. A $0.5 \mathrm{~mL}$ sample of well-mixed slurry was dissolved in $1 \mathrm{~mL}$ of $3 \mathrm{M} \mathrm{HCl}$ for total $\mathrm{Fe}$ analysis. The

234 remaining slurry was vacuum filtered through nylon filters with $0.22 \mu \mathrm{m}$ pores. Aliquots of 0.5

$235 \mathrm{~mL}$ of the filtrate were dissolved in $1 \mathrm{~mL}$ of $3 \mathrm{M} \mathrm{HCl}$ for solution $\mathrm{Fe}$ analysis. Aliquots for total

236 dissolved metal analysis were prepared by acidifying $22 \mathrm{~mL}$ of the filtrate to a final

237 concentration of $2 \% \mathrm{HNO}_{3}\left(22 \mathrm{~mL}\right.$ filtrate and $\left.500 \mu \mathrm{L} \sim 70 \% \mathrm{HNO}_{3}\right)$. The remaining filtrate

238 was sealed in $22 \mathrm{~mL}$ tubes with no headspace for dissolved inorganic carbon and $\mathrm{pH}$ analysis. 
Solids were rinsed in $10 \mathrm{~mL}$ de-ionized water for 24 hours, then dried under anoxic conditions,

240 and finally, ground into powder for analysis.

\subsubsection{Bicarbonate extraction}

Several samples from the variable $\mathrm{U}$, no-Ca series $(1,5$, and $10 \mu \mathrm{MU})$, and one sample

243 from the Ca series $(3 \mu \mathrm{M} \mathrm{U})$ were subjected to a $30 \mathrm{mM} \mathrm{KHCO}_{3}$ extraction to remove and

244 quantify adsorbed U. Bicarbonate extraction of adsorbed uranyl also clarified (via removal of

245 adsorbed species) the X-ray absorption spectrum of non-adsorbed, solid-phase U in these

246 samples. Samples for extraction were harvested as in section 2.1.2 above, but rather than being

247 dried, they were placed in a separate serum vial with $20 \mathrm{~mL}$ of bicarbonate extractant (per bottle

248 of solid sample) and shaken for an additional 4 days at $120 \mathrm{RPM}$. Aliquots of $10 \mathrm{~mL}$ of

249 extractant solution were then taken with a syringe and filtered for ICP-MS analysis in a matrix of

$2502 \% \mathrm{HNO}_{3}$, and the remaining extractant/slurry mixture was vacuum filtered, washed, scraped,

251 dried, and ground into powder for analysis, as in sections 2.1.2 and 2.1.3, above.

Replicate samples from the variable Fe(II) series were also subjected to a $15 \mathrm{mM}$ sodium

253 bicarbonate extraction to quantify adsorbed U. After bicarbonate extraction, solids were filtered

254 on $0.22 \mu \mathrm{m}$ nylon filters, and the extractant solution was preserved in $2 \% \mathrm{HNO}_{3}$ for $\mathrm{U}$ analysis

255 by ICP-MS. Solids were rinsed using $10 \mathrm{~mL}$ of de-ionized water, dried under anoxic conditions, 256 and ground for analysis.

\section{$257 \quad$ 2.1.5. Solution analysis}

Aliquots of reaction medium and extractant solution were analyzed for U using ICP-MS

259 (Thermo Scientific XSERIES 2, Thermo Fisher Scientific, Waltham, MA), and Ca, K, Fe, Na, 260 and Si using ICP-OES (Thermo Scientific ICAP 6300 Dual View, Thermo Fisher Scientific, 
261 Waltham, MA). Samples were diluted in a matrix of $\sim 2 \%$ trace-metal grade nitric acid prior to 262 analysis.

\subsection{Solid phase analyses}

\subsubsection{Ascorbic acid extraction/dissolution experiments}

Quantities of $\sim 10 \mathrm{mg}$ of U-containing iron oxide samples $(10 \mu \mathrm{M}$ and $100 \mu \mathrm{M} \mathrm{U}, 0 \mathrm{mM}$ and $4 \mathrm{mM} \mathrm{Ca}$ ) were dissolved in $50 \mathrm{~mL}$ of $10 \mathrm{mM}$ ascorbic acid at $\mathrm{pH} \sim 3$ in an anoxic atmosphere. The method used was similar to previous studies (Postma, 1993; Larsen and Postma, 2001; Boland et al., 2011). Samples of $1 \mathrm{~mL}$ were taken at 1, 15, 30, 60, 240, and 480 minutes, as well as 1, 2, 4, 6, 12, and 18 days. After 18 days, any remaining solids were completely

270 dissolved by adding $8 \mathrm{~mL}$ of concentrated nitric acid (67-70\% $\mathrm{HNO}_{3}$ by mass) and $2 \mathrm{~mL}$ of

271 concentrated hydrochloric acid $(34-37 \% \mathrm{HCl}$ by mass), in order to obtain total $\mathrm{U}$ and Fe. All

272 solution aliquots were filtered through syringe filters with $0.22 \mu \mathrm{m}$ pores, diluted with de-ionized 273 water, and analyzed via ICP-MS for U, Fe, and Ca.

\subsubsection{X-ray absorption spectroscopy}

A quantity of $\sim 15 \mathrm{mg}$ of dried iron oxide powder was combined with $\sim 70 \mathrm{mg}$ boron nitride powder under oxygen-free conditions, and homogenized by repeated grinding before

277 being pressed into pellets for EXAFS analysis in aluminum sample holders with a double layer

278 of Kapton film. The primary sample holders were then placed into secondary indium-sealed 279 holders with Kapton windows to provide further sample containment and isolation from oxygen 280 during analysis. Ferrihydrite-coated sand samples were not mixed with boron nitride. All 281 samples were analyzed at beamlines 11-2 and 4-1 at SSRL. Data collection was performed at 282 room temperature, under vacuum $\left(\sim 10^{-6}\right.$ torr $)$ to isolate the samples from oxygen and thereby 
283 prevent oxidation. The X-ray beam incident energy was controlled via a $\mathrm{Si}(220)$ double-crystal 284 monochromator in the $\varphi=0^{\circ}$ orientation, detuned $\sim 30 \%$ at $17.6 \mathrm{keV}$ to eliminate higher-order

285 harmonics. Transmission spectra were collected using an in-line ionization chamber, and

286 fluorescence spectra were collected simultaneously using either a 13- or 30-element Ge solid-

287 state detector (Canberra, Connecticut, United States), or a Lytle detector. An in-line Y foil was

288 used to ensure energy calibration; the inflection point in the Y K-edge spectrum (defined using

289 the first-derivative peak) was calibrated to $17038.4 \mathrm{eV}$. Data calibration and averaging were

290 performed using SixPack (Webb, 2005), and data were normalized, background-subtracted, and

291 fit using the Athena and Artemis software packages (Ravel, 2001; Ravel and Newville, 2005)

292 and FEFF 6 or FEFF 8.4 (Ankudinov et al., 1998). Detailed normalization and fitting parameters

293 are provided in the Electronic Annex.

\subsubsection{X-ray powder diffraction}

For X-ray powder diffraction (XRD) analysis, finely ground iron oxide powder was

296 placed into $0.3 \mathrm{~mm}$ diameter borosilicate glass capillaries. Capillaries were flame-sealed on one

297 end, sealed with with five-minute Epoxy (ITW Devcon, Danvers, MA) on the other end, and

298 analyzed at beamline 7-2 at SSRL. Capillaries were contained in sealed polycarbonate containers

299 with Kapton windows. The container was also purged with He gas to prevent exposure to oxygen

300 and decrease the scattering background. The incident beam energy was maintained at $16.5 \mathrm{keV}$

$301(\lambda=0.75 \AA)$; precise energy and diffractometer calibration was achieved using a $\mathrm{LaB}_{6}$

302 calibration standard in a borosilicate glass capillary. Powder diffraction data were collected over

303 a Q-space range of 0.8 to $\sim 10-12 \AA^{-1}$ using a single-channel energy dispersive Vortex solid-state 304 detector. 
306 software package (Larson and Von Dreele, 2000) with the EXPGUI interface (Toby, 2001).

307 Peaks were assigned to goethite, magnetite, and $\mathrm{UO}_{2}$ using molecular models of those minerals.

\subsubsection{Transmission electron microscopy}

Dried, ground samples of the $10 \mu \mathrm{M}$ and $100 \mu \mathrm{M}$ U/iron oxide suspensions (4 mM Ca,

310 prepared as in section 2.1.2) were suspended in ethanol and applied to carbon support grids (Ted

311 Pella, Inc., Redding, California, United States) for examination via transmission electron

312 microscopy (TEM) and energy-dispersive X-ray spectroscopy (EDS). Preparation of TEM grids

313 was carried out in an anoxic atmosphere $\left(95 \% \mathrm{~N}_{2}, 5 \% \mathrm{H}_{2}\right)$, and samples were stored and

314 transported in an anoxic atmosphere until transfer to the TEM vacuum chamber. Samples were

315 analyzed at the Stanford Nanocharacterization Laboratory using a FEI Tecnai G2 F20 X-TWIN

316 Transmission Electron Microscope (FEI, Hillsboro, Oregon, United States). The field emission

317 gun TEM was operated at an accelerating voltage of $200 \mathrm{kV}$, and images were collected using a 318 CCD camera.

\subsubsection{X-ray photoelectron spectroscopy}

Samples of $10 \mu \mathrm{M}$ and $100 \mu \mathrm{M}$ U/iron oxide suspensions prepared as in section 2.1.2

321 (both $4 \mathrm{mM} \mathrm{Ca}$ and no-Ca systems, with $0.3 \mathrm{mM} \mathrm{Fe}(\mathrm{II})$ ) were filtered, rinsed with de-gassed DI

322 water, dried, fixed on indium coupons, and transferred into the analysis chamber through an

323 anoxic glovebox attached to the instrument for X-ray photoelectron spectroscopic (XPS)

324 analysis. The samples were analyzed using a Kratos Axis Ultra DLD spectrometer at room

325 temperature. The instrument was operated at an excitation voltage of $15 \mathrm{kV}$ with a $10 \mathrm{~mA}$

326 current, using monochromatic Al Ka X-rays (1486.7 eV). A pass energy of 20 or $40 \mathrm{eV}$, with a 
327 step size of 0.1 or $0.125 \mathrm{eV}$, enabled high-resolution analysis, with high collection efficiencies

328 achieved using a magnetic immersion lens. Binding energies were referenced to the adventitious

$329 \mathrm{C} 1 \mathrm{~s}$ peak at $285.0 \mathrm{eV}$.

330 The primary and satellite peaks for U4f were used in the fitting procedure following the 331 methodology outlined in Ilton et al. (2010) and Ilton and Bagus (2011). High-resolution U4f

332 regional spectra, spanning a spectral region from $375 \mathrm{eV}$ to $405 \mathrm{eV}$, were best fit after Shirley

333 background subtractions by nonlinear least-squares using the CasaXPS curve resolution

334 software, with parameters similar to those in Ilton et al. (2010).

\section{3. Results}

\subsection{Variable U incubations}

Variable concentrations (1-170 $\mu \mathrm{M} \mathrm{U})$ of uranyl were reacted with ferrihydrite and 300 $\mu \mathrm{M} F(\mathrm{II})$ at $\mathrm{pH} 7.0$, with $0 \mathrm{mM}$ or $4 \mathrm{mM} \mathrm{Ca}$; Fe(II) was used to drive the reductive

339 transformation of both ferrihydrite and $\mathrm{U}$. In the absence of $\mathrm{Ca}$, near complete sorption of $\mathrm{U}$ 340 occurred at initial aqueous concentrations below $10 \mu \mathrm{M}$; the amount of $\mathrm{U}$ remaining in solution

341 was $\leq 0.01 \mu \mathrm{M}$ (Fig. 1). The presence of calcium increased the aqueous phase concentration ten-

342 fold, owing to the stability of the aqueous uranyl-calcium-carbonato ternary complex. However,

343 greater than $95 \%$ of the initial $U$ was retained on (or in) the solid phase at initial U

344 concentrations of 1 to $10 \mu \mathrm{M}$ (Fig. 1). Uranium retention remained greater than $90 \%$ of the

345 initial $\mathrm{U}$ added at $\left[\mathrm{U}(\mathrm{VI})_{\text {initial }}\right]<170 \mu \mathrm{M}$ in the absence of $\mathrm{Ca}$, but when $\mathrm{Ca}$ was present at a

346 concentration of $4 \mathrm{mM}$ less than $40 \%$ of an initial $170 \mu \mathrm{M} \mathrm{U}$ was retained (Fig. 1). 
When solids resulting from the systems with $\left[\mathrm{U}(\mathrm{VI})_{\text {initial }}=10 \mu \mathrm{M}\right.$ and $100 \mu \mathrm{M}$ were reacted with $10 \mathrm{mM}$ ascorbic acid at $\mathrm{pH} \sim 3.0$, approximately $20-40 \%$ of solid-phase $\mathrm{U}$ was removed from the solid within $1 \mathrm{~h}$ of reaction; Fe dissolution was not observed during this

350 reaction period (Fig. 2). The release of $U$ during the initial $1 \mathrm{~h}$ period is attributed to desorption

351 of uranyl from the iron oxide surface. Iron oxide dissolution was slow, as was further U release,

352 with $58-83 \%$ of both total Fe and total $\mathrm{U}$ being released from the solid phase after $18 \mathrm{~d}$ of

353 reaction with ascorbic acid (Fig. 2). On the basis of the ascorbic acid extraction, it appears that

354 less than $40 \%$ of the $U$ was retained on the iron oxide surface, with the remainder occluded

355 within the Fe solid. Further, the U within the iron oxides underwent retarded release upon 356 reaction with ascorbic acid due to the slow dissolution rate of the host minerals.

\subsubsection{Uranium solid phase speciation} combination fitting. On the basis of $U$ axial oxygen coordination, approximately $15 \%$ of the

360 "incorporated" reference spectrum (after bicarbonate extraction) was an un-extracted uranyl 361 species, either adsorbed or otherwise occluded in the iron oxide (Fig. 3), while the remainder 362 (85\%) was U in octahedral (uranate) coordination. Adsorbed and "nano"- $\mathrm{UO}_{2}$ compounds used 363 for linear combination fitting reference spectra were entirely adsorbed uranyl or $\mathrm{UO}_{2}$ (see 364 Electronic Annex for fitting details). Linear combination fits (details of which are provided in 365 Electronic Annex) were adequate to describe the EXAFS function for the fitting region of $k=3$ 366 to $11 \AA^{-1}$ (Fig. 4 and Electronic Annex); in all cases, the reduced chi-squared reported by Athena 367 was $<0.33$, and the $r$-factor was $<0.22$. The uncertainty associated with the linear combination 368 fitting results is $\pm 5-15 \%$ (details on uncertainty estimates are provided in the Electronic Annex). 
Uranium $\mathrm{L}_{3}$-edge EXAFS linear combination fits were performed to quantify the

370 proportion of $\mathrm{U}$ retained in each form (adsorbed $\mathrm{U}$, incorporated $\mathrm{U}$, and $\mathrm{UO}_{2}$ ). Incubations with

$371 \mathrm{U}$ concentrations $\leq 10 \mu \mathrm{M}$ had EXAFS features of adsorbed and incorporated U: 11-36\%

372 adsorbed uranyl and $64-89 \%$ incorporated $U$ for $U$ concentrations of 1 to $10 \mu \mathrm{M}$ in the presence

373 and absence of $\mathrm{Ca}$ (Fig. 5). The range of EXAFS-derived adsorbed uranyl is consistent with the

$374 \mathrm{KHCO}_{3}$ and ascorbic extractions for these samples (data not shown).

At U(VI) concentrations $\geq 50 \mu \mathrm{M}$, the EXAFS spectra also had primarily features of

376 adsorbed and incorporated U (Fig. 5), but all except one also included $\mathrm{UO}_{2}$ (9-32\%). All XRD

377 patterns except for the $170 \mu \mathrm{M} U$ no-Ca slurry showed a low-intensity set of peaks characteristic

378 of uraninite (Fig. 6), corroborating the EXAFS fitting results. Further, uraninite particles were

379 observed using TEM, which occurred as $\sim 10 \mathrm{~nm}$ domains associated with the iron oxides (Fig.

380 7). The EXAFS linear combination fitting shows the variation in adsorbed uranyl, incorporated

$381 \mathrm{U}$, and uraninite with changes in reaction conditions (Fig. 5). In contrast to the reactions with

382 ferrihydrite slurry, an incubation with $0.3 \mathrm{mM} \mathrm{Fe}(\mathrm{II}), 4 \mathrm{mM} \mathrm{Ca}, 170 \mu \mathrm{M} \mathrm{U}$, and ferrihydrite-

383 coated sand resulted in $64 \%$ adsorbed $U$ and $36 \%$ incorporated $U$ (see Electronic Annex). The

384 decreased prevalence of $U$ incorporation in Fe-coated sand is likely attributable to the effects of

385 dissolved/adsorbed silicate on U incorporation and iron oxide transformation (Jones et al., 2009;

386 Boland et al., 2011). No uraninite was observed in the ferrihydrite-coated sand incubation.

Evidence of Ca-U precipitates was not observed. Digestion of solids and analysis via

ICP-MS found Ca to be below detection limit $(<0.1 \mathrm{mg} / \mathrm{L})$ in all cases. Additionally, $\mathrm{Ca} / \mathrm{U}$

389 precipitates were not observed with TEM. Compositional analysis via EDS showed U associated

390 with goethite and other iron oxide particles (resembling bernalite-like particles, or ferrihydrite),

391 but no Ca was detected (data not shown). Further, Ca was not detected in XPS survey scans after 
392 the samples were rinsed with de-ionized water, further suggesting that $\mathrm{Ca}-\mathrm{U}$ precipitates were

393 either not present in this system, or were rinsed off during sample harvesting. Therefore, $U$ in

394 this system was determined to be associated with iron oxide minerals (ferrihydrite, goethite,

395 magnetite) and $\mathrm{U}$ minerals $\left(\mathrm{UO}_{2}\right)$.

\subsubsection{Uranium valence state}

While X-ray absorption spectroscopy can readily distinguish between U(IV) and U(VI), it

398 is less straightforward for differentiating between $\mathrm{U}(\mathrm{VI})$ and $\mathrm{U}(\mathrm{V})$ unless one has a priori

399 structural models (Soldatov et al., 2007). By contrast, XPS has proven sufficient to resolve U(V)

400 (Ilton et al., 2010; Ilton and Bagus, 2011; Ilton et al., 2012); we therefore utilized XPS to

401 determine the valence state of $U$ associated with the iron oxide reaction products. X-ray

402 photoelectron spectroscopic analysis indicates that $\mathrm{U}(\mathrm{V})$ is the dominant oxidation state of $\mathrm{U}$

403 associated with goethite (Fig. 8). U(V) has a lower binding energy than U(VI), commonly

404 corresponding to an approximately $-1 \mathrm{eV}$ shift in the primary $\mathrm{U}_{4} \mathrm{f}_{7 / 2}$ and $\mathrm{U}_{4} \mathrm{f}_{5 / 2}$ peaks; however,

405 the peak shift is supportive but not diagnostic of U(V) (Ilton and Bagus, 2011). The satellite peak

406 structures are needed to distinguish between U(IV), U(V), and U(VI), as described by Ilton et al.

407 (2012). Fig. 8 depicts an XPS spectrum representative of $U$ associated with the iron oxides,

408 which was fit with contributions from U(IV), U(V), and U(VI) at $380.4 \mathrm{eV}, 380.6 \mathrm{eV}$, and 382.0

$409 \mathrm{eV}$, respectively, for the $\mathrm{U}_{4 \mathrm{f}_{7 / 2}}$ peak (Table 1). The $\mathrm{U} 4 \mathrm{f}_{7 / 2}$ satellite peak at $+8.4 \mathrm{eV}$ from the

410 primary peak and the $\mathrm{U}_{4} \mathrm{f}_{5 / 2}$ satellite peak at $+8.3 \mathrm{eV}$ are indicative of $\mathrm{U}(\mathrm{V})$ (Fig. 8). The XPS

411 fits also indicate the presence of both $\mathrm{U}(\mathrm{IV})$ and $\mathrm{U}(\mathrm{VI})$; satellite peaks at $+6.8 \mathrm{eV}$ from the

412 primary peaks are from $\mathrm{U}(\mathrm{IV})$, and satellite peaks at $+3.2 \mathrm{eV}$ are from $\mathrm{U}(\mathrm{VI})$ (Fig. 8).

413 The dominant U oxidation state determined by XPS was U(V), with 56-61\% as U(V) (for

$41410 \mu \mathrm{M}$ and $100 \mu \mathrm{M} \mathrm{U}$, respectively) with $0 \mathrm{mM} \mathrm{Ca}$. With $4 \mathrm{mM} \mathrm{Ca}, 51 \%$ was $\mathrm{U}(\mathrm{V})$ at both 10 
$415 \mu \mathrm{M}$ and $100 \mu \mathrm{M} U$ concentrations. Uranium(VI) was present in all samples (11-26\%), as was

416 U(IV) (22-29\%). Full XPS fitting results are shown in Table 1.

\section{3.1.3. Ferrihydrite transformation products}

Goethite was the only observed crystalline iron oxide in the $0.3 \mathrm{mM} \mathrm{Fe}(\mathrm{II})$, variable-U

experiments. Iron K-edge EXAFS spectroscopy indicates that approximately $30 \%$ of the post-

transformation iron oxide remains as ferrihydrite and $70 \%$ is goethite (see Electronic Annex).

\subsubsection{Amount of uranium incorporated in goethite}

Direct dissolution provides a measurement of the total U:Fe ratio of the solids for the 10 $\mu \mathrm{M}\left[\mathrm{U}(\mathrm{VI})_{\text {initial }}\right]$ and $100 \mu \mathrm{M}\left[\mathrm{U}(\mathrm{VI})_{\text {initial }}\right]$ systems. These can be combined with proportional

424 estimates of incorporated U derived from EXAFS spectroscopy (Fig. 5) to establish an estimate

425 of the amount of incorporated U. Upon acid digestion, the total U:Fe molar ratio of the $10 \mu \mathrm{M}$

$426\left[\mathrm{U}(\mathrm{VI})_{\text {initial }}\right]$ and $100 \mu \mathrm{M}\left[\mathrm{U}(\mathrm{VI})_{\text {initial }}\right], 4 \mathrm{mM}$ Ca systems were 0.0061 and 0.034 , respectively.

427 Combined with the EXAFS spectroscopic estimates (Fig. 5), 0.4 mol\% and $2.3 \mathrm{~mol} \%$ U were

428 incorporated, respectively. This estimate is close to the 2-3 mol\% estimate of Nico et al. (2009)

429 for a similar system with $\mathrm{Ca}$. For the system without $\mathrm{Ca}$, the total $\mathrm{U}: \mathrm{Fe}$ molar ratios were 0.0076 430 and 0.062 , in the $10 \mu \mathrm{M}$ and $100 \mu \mathrm{M}$ [U(VI) $\left.)_{\text {initial }}\right]$, respectively. Taking the EXAFS results into

431 account, this corresponds to incorporated $\mathrm{U}$ of $0.7 \mathrm{~mol} \%$ and $5.2 \mathrm{~mol} \%$ in the no-Ca system.

With ferrihydrite-coated sand, $\sim 2.3 \mathrm{~mol} \%$ (U:Fe) was sorbed to the solid, as measured by

433 difference from $\mathrm{U}$ in solution $(23 \%$ of the $170 \mu \mathrm{M} \mathrm{U}$ in the system was sorbed, $77 \%$ remained in

434 solution). Of this sorbed U, 36\% ( 0.8 mol\%) was incorporated and $64 \%(\sim 1.5 \mathrm{~mol} \%)$ was

435 adsorbed, an amount of $U$ incorporation lower than that observed by Nico et al. (2009). The 
436 difference in amount of incorporation was due to the presence of ten times more Fe(II) to drive U

437 and Fe transformations in Nico et al. (2009).

\subsection{Variable $\mathrm{Fe}(\mathrm{II})$ incubations}

Variable concentrations (0-3 mM Fe) of Fe(II) were reacted with ferrihydrite and $127 \mu \mathrm{M}$ uranyl at a starting $\mathrm{pH}$ of $7.0(3 \mathrm{mM} \mathrm{Fe})$ to $7.5(0 \mathrm{mM} \mathrm{Fe})$, with $0 \mathrm{mM}$ or $4 \mathrm{mM} \mathrm{Ca}$. Iron(II) was used to drive the reductive transformation of both ferrihydrite and $\mathrm{U}$. In the absence of $\mathrm{Ca}$ and $\mathrm{Fe}(\mathrm{II}), 73 \%$ of total $\mathrm{U}$ was adsorbed on ferrihydrite. Addition of Fe(II) resulted in greater $\mathrm{U}$ removal from solution due to $\mathrm{U}$ incorporation into restructured iron oxides and $\mathrm{U}$ reduction to

$444 \mathrm{UO}_{2} ; 79 \%$ of $\mathrm{U}$ was removed from solution at an initial $\mathrm{Fe}(\mathrm{II})$ concentration of $0.3 \mathrm{mM}$, and > 99\% of $U$ was removed from solution at $\mathrm{Fe}(\mathrm{II})$ concentrations of $\geq 1 \mathrm{mM}$ (Fig. 9). In contrast, 446 due to the formation of the uranyl-calcium-carbonato complex with $4 \mathrm{mM}$ Ca present, only $29 \%$ 447 of $U$ was adsorbed when Fe(II) was absent. After Fe(II) addition, 36\% of U was removed from 448 solution at $0.3 \mathrm{mM} \mathrm{Fe}(\mathrm{II})$, while $85 \%$ was removed with $1 \mathrm{mM} \mathrm{Fe}(\mathrm{II})$, and greater than $99 \%$ of $\mathrm{U}$

449 was removed from solution at $3 \mathrm{mM}$ Fe(II) concentrations (Fig. 9). Greater U removal (79$99 \%+$ ) was due largely to $\mathrm{U}$ reduction to $\mathrm{UO}_{2}$, especially at $3 \mathrm{mM} \mathrm{Fe(II),} \mathrm{although} \mathrm{U}$

451 incorporation in goethite, and to a lesser extent uranyl adsorption, also played a role (Fig. 10).

\subsubsection{Uranium solid phase speciation}

At $\left[\mathrm{Fe}(\mathrm{II})_{\text {initial }}\right]=0.3 \mathrm{mM}$, EXAFS linear combination fits showed that only $14 \%$ and $25 \%$

454 of solid phase $\mathrm{U}$ was incorporated into goethite for the $0 \mathrm{mM} \mathrm{Ca}$ and $4 \mathrm{mM} \mathrm{Ca}$ systems,

455 respectively. The remainder of solid phase $\mathrm{U}$ for the lowest Fe(II) concentration was as adsorbed

456 uranyl (Fig. 10). At higher Fe(II) concentrations (1 $\mathrm{mM}$ and $3 \mathrm{mM}), \mathrm{UO}_{2}$ and $\mathrm{U}(\mathrm{V})$ incorporation

457 into goethite become prominent sinks of retained $\mathrm{U}$. In the presence of $4 \mathrm{mM} \mathrm{Ca}$, reaction of 
ferrihydrite with $1 \mathrm{mM} F(\mathrm{II})$ resulted in $62 \%$ incorporated $\mathrm{U}, 38 \%$ as $\mathrm{UO}_{2}$, and no remaining

459 adsorbed uranyl (Fig. 10). At [Fe(II) $\left.)_{\text {initial }}\right]=3 \mathrm{mM}$ and with $4 \mathrm{mM} \mathrm{Ca}, 41 \%$ of the solid phase U

460 was incorporated as $\mathrm{U}(\mathrm{V})$ in goethite, $41 \%$ was reduced to $\mathrm{UO}_{2}$, and $18 \%$ remained adsorbed

461 (Fig. 10). With no $\mathrm{Ca}$, at $\left[\mathrm{Fe}(\mathrm{II})_{\text {initial }}\right]=1 \mathrm{mM}, 54 \%$ of solid phase $\mathrm{U}$ was incorporated, $31 \%$ was

462 reduced to $\mathrm{UO}_{2}$, and $15 \%$ remained adsorbed. When [ $\left.\mathrm{Fe}(\mathrm{II})_{\text {initial }}\right]$ was increased to $3 \mathrm{mM}$ with no

$463 \mathrm{Ca}, 35 \%$ of solid phase $\mathrm{U}$ was incorporated, $44 \%$ was reduced to $\mathrm{UO}_{2}$, and $21 \%$ remained

464 adsorbed (Fig. 10). X-ray powder diffraction indicates that $\mathrm{UO}_{2}$ is present in all of the samples

465 except those with $0.3 \mathrm{mM}$ Fe(II). Samples with $1 \mathrm{mM}$, and $3 \mathrm{mM}$ Fe(II) clearly show the

466 presence of $\mathrm{UO}_{2}$, with both $0 \mathrm{mM}$ and $4 \mathrm{mM} \mathrm{Ca}$ (Fig. 11). The XRD patterns corroborate the $\mathrm{U}$

$467 \mathrm{~L}_{3}$-edge EXAFS linear combination fitting results of $0-44 \% \mathrm{UO}_{2}$; the $\mathrm{UO}_{2}$ is evident in the $\mathrm{U} \mathrm{L}_{3^{-}}$

468 edge EXAFS spectra from the $1 \mathrm{mM}$ and $3 \mathrm{mM} \mathrm{Fe}(\mathrm{II})$ systems, but not the $0.3 \mathrm{mM}$ Fe(II) system 469 (Fig. 12).

Without $\mathrm{Ca}$, the amount of bicarbonate extractable $\mathrm{U}$ varied from $45 \%$ of total $\mathrm{U}$ with 0 $\mathrm{mM} \mathrm{Fe}$ (II) to $38 \%$ with $0.3 \mathrm{mM} \mathrm{Fe}(\mathrm{II})$, down to $\sim 0 \%$ for $1 \mathrm{mM} \mathrm{Fe}(\mathrm{II})$ and $\sim 2 \%$ for $3 \mathrm{mM} \mathrm{Fe}(\mathrm{II})$.

472 The presence of $\mathrm{Ca}$ and the strength of the ternary uranyl-calcium-carbonato complex altered the 473 amount of bicarbonate extractable uranyl to $16 \%$ with no $\mathrm{Fe}(\mathrm{II}), 16 \%$ with $0.3 \mathrm{mM} \mathrm{Fe}(\mathrm{II}), \sim 3 \%$

474 with $1 \mathrm{mM} \mathrm{Fe}(\mathrm{II})$, and $\sim 0 \%$ for $3 \mathrm{mM} \mathrm{Fe}(\mathrm{II})$. Up to half of the adsorbed uranyl (as measured

475 spectroscopically) was not removed by bicarbonate extraction in the $0.3 \mathrm{mM} \mathrm{Fe}(\mathrm{II})$ system, and 476 almost no adsorbed uranyl was removed by bicarbonate extraction in the $1 \mathrm{mM}$ and $3 \mathrm{mM} F e(\mathrm{II})$ 477 systems.

\section{$478 \quad$ 3.2.2. Ferrihydrite transformation products}

With an initial $\mathrm{Fe}(\mathrm{II})$ concentration of $0.3 \mathrm{mM}$, goethite with short, broad diffraction

480 peaks was the primary observed transformation product of ferrihydrite, though the presence of 
481 Ca led to goethite with sharper diffraction peaks (Fig. 11). Substantial scattering background, 482 presumably from residual 2-line ferrihydrite, is also present at $\left[\mathrm{Fe}(\mathrm{II})_{\text {initial }}\right]=0.3 \mathrm{mM}$. At an 483 initial $\mathrm{Fe}(\mathrm{II})$ concentration of $1 \mathrm{mM}$, goethite with sharp diffraction peaks was the only iron 484 oxide detected in the XRD analysis. At $3 \mathrm{mM} \mathrm{Fe}(\mathrm{II})$, magnetite was the primary Fe product, with 485 smaller amounts of goethite (Fig. 11).

\section{4. Discussion}

\subsection{Competition between reaction pathways}

In combination with uranyl adsorption, the fate of $U$ within our experimental system is dependent on multiple different Fe(II)-driven processes, which all potentially occur

490 simultaneously: U incorporation into goethite during Fe(II)-catalyzed ferrihydrite transformation

491 to goethite, and $\mathrm{Fe}(\mathrm{II})$-induced uranyl reduction to $\mathrm{UO}_{2}$ (Fig. 13). The fate of $\mathrm{U}$ in the system

492 depends on the relative reaction rates of a suite of competing reactions. The reactions governing

$493 \mathrm{U}$ fate are (all reactants/products are aqueous species unless otherwise specified):

$$
\mathrm{Fe}(\mathrm{OH})_{3(s)}+\mathrm{Fe}^{2+} \rightleftharpoons \mathrm{FeOOH}_{(s)}+\mathrm{H}_{2} \mathrm{O}+\mathrm{Fe}^{2+}
$$

- $\quad \mathrm{U}(\mathrm{VI})$ reduction to $\mathrm{UO}_{2}$ :

$$
\mathrm{UO}_{2}\left(\mathrm{CO}_{3}\right)_{3}{ }^{4-}+2 \mathrm{Fe}^{2+}+6 \mathrm{H}_{2} \mathrm{O} \rightleftharpoons \mathrm{UO}_{2(s)}+2 \mathrm{Fe}(\mathrm{OH})_{3(s)}+3 \mathrm{HCO}_{3}{ }^{-}+3 \mathrm{H}^{+}
$$

For the uranyl-calcium-carbonato species,

$$
\mathrm{UO}_{2} \mathrm{Ca}_{2}\left(\mathrm{CO}_{3}\right)_{3}{ }^{0}+2 \mathrm{Fe}^{2+}+6 \mathrm{H}_{2} \mathrm{O} \rightleftharpoons
$$




$$
\mathrm{UO}_{2(s)}+2 \mathrm{Fe}(\mathrm{OH})_{3(s)}+2 \mathrm{Ca}^{2+}+3 \mathrm{HCO}_{3}^{-}+3 \mathrm{H}^{+}
$$

- $U(V)$ incorporation, considering uranyl and uranyl-carbonato adsorption complexes: factors that affect the kinetics of, and subsequent competition between, reaction pathways include: (1) Fe(II) concentration; (2) U concentration; (3) pH; and (4) Ca concentration (in the presence of carbonate). The first three factors, $\mathrm{Fe}(\mathrm{II})$ and $\mathrm{U}$ concentrations, and $\mathrm{pH}$, exert strong

513 controls due to their effects on iron oxide transformation and the thermodynamic favorability of 514 U reduction. The most important parameter in determining iron oxide products and $\mathrm{U}$ fate is $515 \mathrm{Fe}(\mathrm{II})$ concentration, due to its central role in the three competing reactions of ferrihydrite 516 transformation, $\mathrm{U}(\mathrm{VI})$ reduction, and $\mathrm{U}(\mathrm{V})$ incorporation. Calcium modifies these overall 517 pathways due to its effects on uranyl aqueous speciation, with higher $\mathrm{U}$ concentrations favoring 518 reduction and the presence of $\mathrm{Ca}$ retarding reduction. Ferrihydrite transformation is affected by $\mathrm{pH}$ and $\mathrm{Fe}(\mathrm{II})$ concentration, with higher $\mathrm{pH}$ or

520 Fe(II) favoring magnetite and lower $\mathrm{pH}$ or Fe(II) favoring goethite (Hansel et al., 2005). The $\mathrm{pH}$ 521 of the system, as well as Fe(II) concentrations, can also affect iron oxide transformation kinetics. 522 For example, Yang et al. (2010) found that Fe(II)-induced transformation of 6-line ferrihydrite to 523 goethite and/or magnetite occurred at $\mathrm{pH} 6.8$ on a timescale of days to several weeks. Boland et 
524 al. (2011) observed that 2-line ferrihydrite transformed to goethite within 4 days at $\mathrm{pH} 6.5$ in the 525 presence of $1 \mathrm{mM} \mathrm{Fe}$ (II). Hansel et al. (2005) observed the transformation of 2-line ferrihydrite $526 \sim 70 \%$ goethite and $\sim 30 \%$ ferrihydrite within $12 \mathrm{~h}$ at $\mathrm{pH} 7.2$ upon reaction with $2 \mathrm{mM} \mathrm{FeSO}_{4}$, but 527 with $0.2 \mathrm{mM} \mathrm{FeSO}_{4}$, the transformation to a mixture of goethite and lepidocrocite took $\sim 40 \mathrm{~h}$.

528 Ferrihydrite transformation products and reaction kinetics are the result of an intimate interplay 529 between $\mathrm{Fe}(\mathrm{II})$ concentrations and $\mathrm{pH}$. In our system, a slight difference in initial $\mathrm{pH}$ led to 530 strikingly different ferrihydrite transformation products in otherwise similar systems with 300 $531 \mu \mathrm{M} \mathrm{Fe}(\mathrm{II})$ and $100+\mu \mathrm{M} \mathrm{U}$ (e.g., Figs. 6 and 11). The inhibition of goethite formation at higher $532 \mathrm{pH}$ is consistent with previous studies (Hansel et al., 2005). The slight $\mathrm{pH}$ increase also produced 533 strikingly different results with respect to U incorporation, since the decrease in goethite 534 formation corresponded with a decrease in U incorporation (Figs. 5 and 10). In addition to ferrihydrite transformation kinetics, $\mathrm{U}$ redox reaction kinetics also play a 536 key role in the evolution of the system. The abiotic reduction of $\mathrm{U}(\mathrm{VI})$ to $\mathrm{UO}_{2}$ may occur more 537 rapidly than iron oxide transformation. Liger et al. (1999) observed the reduction of $0.5 \mu \mathrm{M} U$ by $538160 \mu \mathrm{M} \mathrm{Fe}(\mathrm{II})$ in the presence of a hematite suspension in less than $30 \mathrm{~h}$. Du et al. (2011) found 539 that $0.21 \mathrm{mM} \mathrm{U}(\mathrm{VI})$ was completely reduced by $1 \mathrm{mM} \mathrm{Fe}(\mathrm{II})$ at $\mathrm{pH} \sim 8.9$ in $\sim 20$ minutes, and that 540 a pH $\sim 6.2$ substantially slowed but did not completely inhibit $\mathrm{U}$ reduction. Faster $\mathrm{UO}_{2}$ 541 precipitation relative to goethite formation led to substantially more $\mathrm{UO}_{2}$ in the $1 \mathrm{mM} \mathrm{Fe}$ (II) 542 system (Fig. 10) versus a comparable system at a slightly lower initial pH with $300 \mu \mathrm{M} \mathrm{Fe}$ (II)

543 (Fig. 5, $100 \mu \mathrm{M} \mathrm{U}$ ). The interplay between variations in reaction conditions and vastly differing 544 reaction kinetics and products illustrates the complexity of the U/ferrihydrite/Fe(II) system.

545 We observed that for $\mathrm{U}$ concentrations ranging from 1 to $10 \mu \mathrm{M}, \mathrm{U}$ incorporation into 546 goethite is the dominant retention pathway, ranging from 64 to $89 \%$ depending on the reaction 
547 conditions (Fig. 5). Under conditions leading to Fe(II) production such as in an aquifer in low-

548 oxygen conditions, therefore, $\mathrm{U}$ incorporation into goethite is likely an important and overlooked

549 retention pathway at $\mathrm{U}$ concentrations $<10 \mu \mathrm{M}$ (in cases where $\mathrm{Fe}(\mathrm{II})$ concentrations are on the

550 order of hundreds of $\mu \mathrm{M}$ ). Boland et al. (2011) also observed $\mathrm{U}$ incorporation into goethite for

551 similar conditions with one important distinction being that both calcium and carbonate were

552 absent in their system. Given the substantial impact of carbonate and calcium on $\mathrm{U}$

553 biogeochemistry, and the ubiquity of both ions in the environment, the present findings

554 substantiate the competitiveness of the $\mathrm{U}$ incorporation process in low-U systems containing

555 carbonate and Ca.

Uranium incorporation into goethite is a dominant $U$ retention pathway in low-U

557 systems, and is also a competitive $\mathrm{U}$ retention pathway across the wide range of aqueous reaction 558 conditions explored in this study. Incorporated $\mathrm{U}$ is a substantial component of the total $\mathrm{U}$ budget

559 in all systems studied here (Figs. 1, 5, 9, and 10). The relative contributions of the $\mathrm{UO}_{2}$ pathway,

560 however, increased with increasing initial aqueous $U$ concentration, until consumption of Fe(II)

561 limited further U reduction to U(IV). Generally, when Fe(II) concentration was not limiting,

562 higher $\mathrm{U}$ concentrations accelerated $\mathrm{U}(\mathrm{VI})$ reduction to $\mathrm{U}(\mathrm{IV})$, resulting in subsequent

563 precipitation of $\mathrm{UO}_{2}$ becoming an increasingly prominent retention pathway. Even with initial

564 concentrations of $\mathrm{Fe}(\mathrm{II})$ as high as $3 \mathrm{mM}$, however, $\mathrm{U}$ incorporation into goethite remained a

565 contributing retention pathway (Fig. 10).

\section{4.2. Effect of uranyl aqueous speciation}

While the presence of calcium decreased U retention (Figs. 1 and 9) and the amount of $U$

568 incorporated into iron oxide, EXAFS analysis demonstrated that $\mathrm{U}$ incorporation remained an

569 operative retention process (Figs. 5 and 10). Boland et al. (2011) achieved similar EXAFS results 
570 in systems absent of carbonate, suggesting that $\mathrm{U}$ incorporation into ferrihydrite during $\mathrm{Fe}(\mathrm{II})-$

571 induced transformation does not require a particular $\mathrm{U}$ aqueous species. In the present study, $\mathrm{U}$

572 incorporation occurred, and was an important sequestration process, regardless of the dominant

573 uranyl aqueous species. Incorporation occurred even though uranyl-carbonato and uranyl-

574 calcium-carbonato complexes decreased the extent of U adsorption (Waite et al., 1994; Stewart

575 et al., 2010) (Figs. 1 and 9). The fraction of adsorbed uranyl, even when decreased by the uranyl-

576 calcium-carbonato complexes, appears to provide ample precursor concentration for $\mathrm{U}$

577 incorporation.

578 Despite the relative lack of impact of calcium on the U incorporation process, as shown

579 by the EXAFS linear combination fitting analysis (Figs. 5 and 10), the presence of uranyl-

580 calcium-carbonato ternary complexes can substantially impact the fate of $U$ by altering the mass

581 balance (Figs. 1 and 9) and exerting a secondary influence on solid phase products. Uranyl-

582 calcium-carbonato ternary complexation decreases the rate and extent of $\mathrm{U}(\mathrm{VI})$ reduction to

583 U(IV) compared to Ca-free systems (Brooks et al., 2003; Hua et al., 2006; Neiss et al., 2007),

584 and thus increased the proportion of incorporated $\mathrm{U}$ relative to $\mathrm{UO}_{2}$ (at $\left[\mathrm{Fe}(\mathrm{II})_{\text {initial }}\right] \geq 1 \mathrm{mM}$ ).

585 Consequently, when Fe(II) is not limiting, proportionally more incorporated U occurs under

586 conditions conducive to the formation of uranyl-calcium-carbonato ternary complexes (Fig. 10).

587 At lower $\mathrm{Fe}(\mathrm{II})$ concentrations, $\left[\mathrm{Fe}(\mathrm{II})_{\text {initial }}\right]=0.3 \mathrm{mM}$, the presence of uranyl-calcium-carbonato

588 ternary complexes decrease both the rates of $\mathrm{U}$ incorporation and $\mathrm{U}$ reduction to $\mathrm{U}(\mathrm{IV})$, and

589 increase the relative rate of ferrihydrite transformation to goethite. This leads to proportionally

590 more $\mathrm{UO}_{2}$ on the solid, since $\mathrm{U}$ incorporation tapers off as more goethite is formed (Fig. 5).

591 Computations by Wander et al. (2006) suggested that reduction of uranyl-carbonato complexes

592 occurs after Fe(II) binding to the triscarbonato complex; uranyl-calcium-carbonato ternary 
593 complexation likely slows the rate of U reduction by aqueous Fe(II) by partially blocking the

594 binding site of $\mathrm{Fe}(\mathrm{II})$ on the uranyl ternary complex and subsequent electron transfer. A decrease

595 in the rate of $\mathrm{U}$ reduction due to $\mathrm{U}$ ternary complexes would explain the observed differences

596 between $\mathrm{U}$ reduction and $\mathrm{U}$ incorporation in the presence of $\mathrm{Ca}$.

\section{4.3. Uranium valence state and incorporated uranium}

Nico et al. (2009) and Boland et al. (2011) suggested that $\mathrm{U}$ incorporated in goethite might have been in the pentavalent oxidation state. Ilton et al. (2012) provided strong evidence for $\mathrm{U}(\mathrm{V})$ incorporated in the structure of hematite, and atomistic modeling by Kerisit et al. (2011) indicated that $\mathrm{U}(\mathrm{V})$ substitution for $\mathrm{Fe}(\mathrm{III})$ in goethite was a better match to the available EXAFS data than U(VI) or U(IV), assuming a deprotonation charge balance scheme. However,

603 the $\mathrm{U} \mathrm{L}_{3}$-edge $\mathrm{x}$-ray absorption edge cannot be sufficiently resolved to distinguish between $\mathrm{U}(\mathrm{V})$ 604 and $\mathrm{U}(\mathrm{VI})$. Further, post-edge features are chiefly due to uranate coordination geometry rather 605 than U valence state (Farges et al., 1992; Soldatov et al., 2007), and distinguishing between $606 \mathrm{U}(\mathrm{VI})$ and $\mathrm{U}(\mathrm{V})$ depends on qualitative comparison of these features or a priori structural 607 models (e.g., Soldatov et al., 2007). Here, we used XPS to interrogate the valence state of U 608 associated with goethite formed by reductive transformation of ferrihydrite. X-ray photoelectron 609 spectroscopy can distinguish directly and quantitatively between $\mathrm{U}$ valence states using the 610 relative energies of the U4f primary and satellite peaks (Ilton and Bagus, 2011). $\mathrm{X}$-ray photoelectron spectroscopic analysis of $10 \mu \mathrm{M} \mathrm{U}$ and $100 \mu \mathrm{M} \mathrm{U}$ goethite samples

612 in the present study indicated that the dominant oxidation state is $\mathrm{U}(\mathrm{V})$ (Fig. 8). There is good 613 agreement between EXAFS-derived and XPS-derived estimates of U(VI) and U(V), with the 614 caveat that the surface-sensitivity of the XPS technique may underestimate U(V) if it is

615 incorporated in the goethite structure. We do observe such an under-estimation (by 20-30\%) of 
$\mathrm{U}(\mathrm{V})$ in the XPS measurements relative to EXAFS-derived estimates of incorporated U.

617 Furthermore, trends in the data with increasing initial aqueous $U$ concentration, such as an

618 increase in surface-associated $\mathrm{UO}_{2}$ particles (i.e., U(IV) in the XPS measurements), are

619 consistent with the conclusion that U(IV) and U(VI) are predominantly surface-associated, while

$620 \mathrm{U}(\mathrm{V})$ is incorporated in the goethite structure itself. The assertion that $\mathrm{U}$ is incorporated in

621 goethite in the pentavalent state is further supported by atomistic modeling (Kerisit et al., 2011).

622 Incorporated U is not likely U(IV) (Kerisit et al., 2011), and the mass balance of separate

623 measurements of $\mathrm{U}$ in these experiments indicates that the major component is incorporated $\mathrm{U}$.

624 Drawing on both theoretical work by Kerisit et al. (2011) and our experimental results, we

625 conclude that incorporated $\mathrm{U}$ is $\mathrm{U}(\mathrm{V})$. temperature $\mathrm{U}$ incorporation into goethite. Indeed, without reduction of $\mathrm{U}$ to $\mathrm{U}(\mathrm{V})$, the transformation from uranyl coordination geometry to uranate coordination geometry may not be 631 possible at ambient temperature on this timescale of days to weeks.

633 or XRD data; the surface-sensitivity of XPS likely accounts for both the systematic under-

634 estimation of U(V) (i.e., incorporated U), and the detection of U(IV), compared to EXAFS. The

635 detection of surface-bound $\mathrm{U}(\mathrm{IV})$ in the $10 \mu \mathrm{M} \mathrm{U}$ samples suggests that some $\mathrm{U}$ in the system

636 may exist as surface-adsorbed, poorly-crystalline or monomeric U(IV). However, the XPS-

637 determined $\mathrm{U}(\mathrm{IV})$ parallels the EXAFS- and TEM-detectable $\mathrm{UO}_{2}$ with increasing aqueous $\mathrm{U}$

638 concentration. This is consistent with the findings of Ilton et al. (2012), where simultaneous 
reduction of $U(V I)$ in hematite and on the surface of hematite yielded $U(V)$ and $U(I V)$, respectively. Consequently, under reducing conditions, pentavalent $\mathrm{U}$ tends to be stabilized within the structures of both hematite and goethite, while U(VI) and U(IV) species may be found associated with the iron oxide surface.

\subsection{Mechanism of pentavalent uranium incorporation}

Uranium incorporates into goethite during the Fe(II)-induced transformation of ferrihydrite under a wide variety of solution conditions. Uranium addition after ferrihydrite transformation yielded only $18 \%$ incorporated $U$ (see Electronic Annex), likely from ferrihydrite formed after reduction of the added U(VI); this indicates the necessity of a ferrihydrite precursor for U incorporation. We along with others (e.g., Duff et al., 2002; Smith et al., 2009) observed that co-precipitation of $\mathrm{U}$ and Fe during ferrihydrite synthesis by hydrolysis does not yield incorporated $\mathrm{U}$. Rather, $\mathrm{U}$ is co-precipitated as distinct uranyl hydroxide phases or as an adsorbed phase. Heating and aging can produce uranate-coordinated $\mathrm{U}$ in iron oxide host phases such as hematite (Duff et al., 2002; Ilton et al., 2012), though Marshall et al. (2014) interpreted the EXAFS spectrum of U substituted for Fe(III) in hematite as uranyl with elongated axial oxygen bonds. Adsorption of $U$ onto ferrihydrite also does not produce incorporated $U$ in the absence of an $\mathrm{Fe}(\mathrm{II})$ - or heat-induced transformation (at least on the timescale of the present study)-although some adsorbed U can be "strongly retained/sorbed" and resistant to chemical extraction. Taken together, this evidence suggests that a redox-induced transformation of U(VI) to $\mathrm{U}(\mathrm{V})$ is necessary to induce $\mathrm{U}$ incorporation into goethite at ambient temperature on timescales of hours to days.

The mechanism of $U$ incorporation into goethite occurs in four steps: (1) adsorption of the uranyl cation on the ferrihydrite surface; (2) binding and electron transfer from $\mathrm{Fe}(\mathrm{II})$ to the 
662 adsorbed uranyl cation, producing U(V) (Fig. 14); (3) a shift in U(V) to octahedral coordination 663 (Fig. 14); and, (4) continued growth of goethite around the U(V) (Fig. 15). In the first step, 664 uranyl adsorption occurs as a mononuclear, bidentate inner-sphere surface complex at $\mathrm{pH} 7$ 665 (Bargar et al., 1999; Rossberg et al., 2009; Hiemstra et al., 2009). In the presence of carbonate, 666 the uranyl cation may act as a bridge between the mineral surface and the carbonate ion at 667 circumneutral $\mathrm{pH}$ (Bargar et al., 1999), though there is disagreement on the nature of the surface 668 complex in the presence of carbonate at $\mathrm{pH}<8$ (Rossberg et al., 2009). In either case, the 669 mononuclear, bidentate inner-sphere uranyl surface complex is the likely precursor of 670 incorporated $\mathrm{U}$, and is the common link between the carbonate-free, carbonate, and calcium671 carbonate systems. In the second step, Fe(II) complexes with the adsorbed uranyl complex, 672 leading to electron transfer and creation of $\mathrm{U}(\mathrm{V})$ and $\mathrm{Fe}(\mathrm{III})$. It is also possible, but seems less 673 likely, that Fe(II) sorbed on ferrihydrite induces electron transfer through the solid (via electron 674 hopping) and ultimately electron donation to adsorbed U(VI). In either case, U(VI) is reduced by $675 \mathrm{Fe}(\mathrm{II})$ to $\mathrm{U}(\mathrm{V})$ on the ferrihydrite surface. The formation of a $\mathrm{U}(\mathrm{V})$ species appears to provide a 676 pathway to overcome a major limitation of uranyl incorporation-a mismatch in coordination of $677 \mathrm{U}$ with that of the cation sites in the goethite (or other iron oxide) lattice. The strong trans-dioxo 678 bonds to axial oxygen atoms within the hexavalent uranyl cation would otherwise inhibit $\mathrm{U}$ 679 incorporation within the iron oxide. The axial oxygen atoms reside at a distance of $\sim 1.8 \AA$ in 680 uranyl, while measurements of incorporated U in this study and others (Nico et al., 2009; Boland 681 et al., 2011; Ilton et al., 2012) indicate a bond distance of 2.10-2.18 $\AA$. There are some solids, 682 such as $\mathrm{RbUO}_{3}$ and $\mathrm{NaUO}_{3}$, where $\mathrm{U}(\mathrm{V})$ exists in octahedral coordination with bond distances in 683 the appropriate range (Burns, 2005; Soldatov et al., 2007). We therefore propose that electron 684 transfer from Fe(II) induces a relaxation of the trans-dioxo bonds and an extension of the bond 
685 length between the U atom and axial O atoms from $1.80 \AA$ to $2.10-2.18 \AA$. The electron transfer 686 also triggers a coordination change from two axial and 5-6 equatorial $\mathrm{O}$ in adsorbed uranyl to 687 octahedral coordination in the incorporated $\mathrm{U}(\mathrm{V})$-the third step in the $\mathrm{U}$ incorporation 688 mechanism (Fig. 14). The fourth and final step in the incorporation mechanism is the formation of an Fe(III), 690 produced by the electron transfer, that is positioned toward the exterior of the mineral relative to 691 the newly-incorporated U(V) (Fig. 14), enabling continued crystal growth of the goethite lattice 692 (Fig. 15). Kerisit et al. (2011) suggested that local charge balance is likely achieved by the 693 protonation or de-protonation of neighboring hydroxyl groups, with the possible formation of a 694 vacancy at a nearby $\mathrm{Fe}(\mathrm{III})$ site. On the basis of our experimentally-determined U-O and U-Fe 695 distances and coordination numbers (given in Table EA1) in comparison with the modeling 696 predictions of Kerisit et al. (2011), de-protonation of hydroxyls is the most likely charge697 balancing mechanism given substitution of $\mathrm{U}$ for $\mathrm{Fe}(\mathrm{III})$. Further, the calculated U(V)-O 698 distances are a better match to the EXAFS data than the calculated U(VI)-O distances. The 699 introduction of a vacancy in a neighboring $\mathrm{Fe}(\mathrm{III})$ site, and the protonation of neighboring 700 hydroxyl, is another possible charge compensation scheme, but the bond distances, coordination 701 numbers, and strain calculated by Kerisit et al. (2011) do not provide support for a coupled $702 \mathrm{Fe}(\mathrm{III})$ vacancy/protonation charge compensation scheme. However, the atomistic modeling 703 approach is purely electrostatic, and future ab initio modeling may modify these conclusions.

704 A representative chemical reaction for Fe(II)-induced U incorporation into goethite 705 during ferrihydrite reductive transformation is given by Equation 3a:

$$
\mathrm{UO}_{2}{ }^{2+}{ }_{(a d s)}-\mathrm{Fe}(\mathrm{OH})_{3(s)}+\mathrm{Fe}^{2+}+\mathrm{H}_{2} \mathrm{O}_{(l)} \rightleftharpoons \mathrm{U}^{\mathrm{V}} \mathrm{Fe}_{2} \mathrm{O}_{5}(\mathrm{OH})_{(s)}+4 \mathrm{H}_{(a q)}^{+}
$$


707 Equation $3 \mathrm{a}_{1}$ shows charge balance achieved by de-protonation only. The reaction with a Fe(III)

708 vacancy and protonation of a hydroxyl is shown by Equation $3 \mathrm{a}_{2}$ :

709

$$
\mathrm{UO}_{2}^{2+}{ }_{(a d s)}-\mathrm{Fe}(\mathrm{OH})_{3(s)}+\mathrm{Fe}^{2+}+3 \mathrm{H}_{2} \mathrm{O}_{(l)} \rightleftharpoons \mathrm{U}^{\mathrm{V}} \mathrm{Fe}_{2} \mathrm{O}_{3}(\mathrm{OH})_{5(s)}+4 \mathrm{H}_{(a q)}^{+}
$$

710 As discussed above, our measurements of $U$ oxidation state and $U$ coordination geometry

711 suggest that Equation $3 a_{1}$ is the likely interpretation of the $U(V)$ incorporation mechanism (Fig. 712 14).

\subsection{Conclusions}

Other investigators (Duff et al., 2002; Ilton et al., 2012) have shown that U can be

715 incorporated into hematite via U/Fe co-precipitation and heating of the resulting solid material to

$71670^{\circ} \mathrm{C}$. We have shown that redox transformation is capable of achieving $\mathrm{U}$ incorporation into

717 goethite at ambient temperatures, and that this transformation occurs within days at U and Fe(II)

718 concentrations that are common in subsurface geochemical environments.

In the presence of ferrihydrite, with $\left[\mathrm{U}_{\text {initial }}\right]$ in the range of $1-170 \mu \mathrm{M}$, and $\left[\mathrm{Fe}(\mathrm{II})_{\text {initial }}\right]$ of

$720300 \mu \mathrm{M}, \mathrm{U}(\mathrm{V})$ incorporation was a dominant $\mathrm{U}$ retention pathway at $\mathrm{pH}$ 7.0. Redox processes

721 including Fe(II)-induced transformation of ferrihydrite to goethite and electron transfer from

$722 \mathrm{Fe}(\mathrm{II})$ to $\mathrm{U}(\mathrm{VI})$ are crucial to the $\mathrm{U}$ incorporation process. Increasing $\mathrm{Fe}(\mathrm{II})$ or $\mathrm{U}$ concentration,

723 or initial $\mathrm{pH}$, made $\mathrm{U}(\mathrm{VI})$ reduction to $\mathrm{U}(\mathrm{IV})$ a more competitive sequestration pathway in this

724 system, presumably by increasing the relative rate of $U$ reduction. Uranium concentrations

725 commonly found in contaminated subsurface environments are often on the order of $1-10 \mu \mathrm{M}$

726 (Anderson et al., 2003; Wu et al., 2006; Yabusaki et al., 2007), and groundwater Fe(II)

727 concentrations can reach levels of 100-300 $\mu \mathrm{M}$ (Anderson et al., 2003) in reduced zones of the

728 subsurface. Though the other necessary reactant, ferrihydrite, is often a transient solid phase in 
these environments, the basic geochemical conditions favoring U(V) incorporation during

730 ferrihydrite transformation are not uncommon in natural or engineered systems. The redox-

731 driven $\mathrm{U}(\mathrm{V})$ incorporation mechanism may help to explain $\mathrm{U}$ retention in some geologic

732 materials, improving our understanding of U-based geochronology and the redox status of

733 ancient geochemical environments. This mechanistic understanding of $U$ incorporation may even

734 lead to new approaches for in situ contamination remediation techniques, and will help refine

735 models of $U$ fate and transport in reduced subsurface zones.

737 Acknowledgements

738 Support for M.M. was provided partially by the Robert and Marvel Kirby Stanford Graduate

739 Fellowship. Additionally, this research was supported by the U.S. Department of Energy Office

740 of Biological and Environmental Research, through the Subsurface Biogeochemical Research

741 program (grant number DE-SC0006772). Funding for J.L.P. was provided by the U.S.

742 Department of Energy Office of Biological and Environmental Research, Climate and

743 Environmental Sciences Division, as part of the SLAC Science Focus Area Research Program

744 (FWP \#10094). E.S.I. was supported by the Geosciences Research Program in the U.S.

745 Department of Energy, Office of Basic Energy Sciences, Division of Chemical Sciences,

746 Geosciences \& Biosciences. A portion of this research was performed using EMSL, a national

747 scientific user facility sponsored by the U.S. Department of Energy's Office of Biological and

748 Environmental Research and located at Pacific Northwest National Laboratory. Use of the

749 Stanford Synchrotron Radiation Lightsource, SLAC National Accelerator Laboratory, is

750 supported by the U.S. Department of Energy, Office of Science, Office of Basic Energy Sciences

751 under Contract No. DE-AC02-76SF00515. The contents of this publication are solely the 
responsibility of the authors and do not necessarily represent the official views of NIGMS, NCRR or NIH. The authors would like to thank Moses Gonzalez and Guangchao Li for their tireless assistance. Further, the authors are indebted to Ann Marshall and Chuck Hitzman at the Stanford Nano Center for their technical expertise and patience. Additional thanks go to Peter S. Nico, and Daniel E. Giammar for their input. Three volunteer peer reviewers for GCA also provided valuable and thought-provoking feedback that substantially improved the manuscript. The authors also appreciate the technical and safety support provided by L. Amoroso, D. Day, A. Gooch, D. Menke, C. Morris, D. Murray, C. Patty, R. Russ, and the rest of the team at SSRL.

\section{References}

Allard T., Ildefonse P., Beaucaire C. and Calas G. (1999) Structural chemistry of uranium associated with $\mathrm{Si}, \mathrm{Al}, \mathrm{Fe}$ gels in a granitic uranium mine. Chem. Geol. 158, 81-103.

Anderson R., Vrionis H., Ortiz-Bernad I., Resch C., Long P., Dayvault R., Karp K., Marutzky S., Metzler D., Peacock A., White D., Lowe M. and Lovley D. (2003) Stimulating the In Situ Activity of Geobacter Species To Remove Uranium from the Groundwater of a UraniumContaminated Aquifer. Appl. Environ. Microbiol. 69, 5884-5891.

Ankudinov A. L., Rehr J. J. and Conradson S. D. (1998) Real-space multiple-scattering calculation and interpretation of x-ray-absorption near-edge structure. Phys. Rev. B 58, 7565-7576.

Bargar J., Reitmeyer R. and Davis J. (1999) Spectroscopic Confirmation of Uranium(VI)Carbonato Adsorption Complexes on Hematite. Environ. Sci. Technol. 33, 2481-2484.

Bernier-Latmani R., Veeramani H., Vecchia E. D., Junier P., Lezama-Pacheco J. S., Suvorova E. I., Sharp J. O., Wigginton N. S. and Bargar J. R. (2010) Non-uraninite Products of Microbial U(VI) Reduction. Environ. Sci. Technol. 44, 9456-9462. 
Boland D. D., Collins R. N., Payne T. E. and Waite T. D. (2011) Effect of Amorphous Fe(III) Oxide Transformation on the Fe(II)-Mediated Reduction of U(VI). Environ. Sci. Technol. 45, 1327-1333.

Boyanov M. I., Fletcher K. E., Kwon M. J., Rui X., O'Loughlin E. J., Löffler F. E. and Kemner K. M. (2011) Solution and Microbial Controls on the Formation of Reduced U(IV) Species. Environ. Sci. Technol. 45, 8336-8344.

Boyanov M. I., O'Loughlin E. J., Roden E. E., Fein J. B. and Kemner K. M. (2007) Adsorption of $\mathrm{Fe}(\mathrm{II})$ and U(VI) to carboxyl-functionalized microspheres: The influence of speciation on uranyl reduction studied by titration and XAFS. Geochimica et Cosmochimica Acta 71, 1898-1912.

Brooks S. C., Taylor D. L. and Jardine P. M. (1996) Reactive transport of EDTA-complexed cobalt in the presence of ferrihydrite. Geochimica et Cosmochimica Acta 60, 1899-1908.

Brooks S., Fredrickson J., Carroll S., Kennedy D., Zachara J., Plymale A., Kelly S., Kemner K. and Fendorf S. (2003) Inhibition of Bacterial U(VI) Reduction by Calcium. Environ Sci Technol 37, 1850-1858.

Burns P. (2005) $\mathrm{U}^{6+}$ Minerals and inorganic compounds: Insights into an expanded structural hierarchy of crystal structures. Canadian Mineralogist 43, 1839-1894.

Burns P. C. and Finch R. J. (1999) Wyartite: Crystallographic evidence for the first pentavalenturanium mineral. American Mineralogist 84, 1456-1460.

Catalano J. G. and Brown G. E. (2004) Analysis of uranyl-bearing phases by EXAFS spectroscopy: Interferences, multiple scattering, accuracy of structural parameters, and spectral differences. American Mineralogist 89, 1004-1021.

Catalano J., Heald S., Zachara J. and Brown G. (2004) Spectroscopic and Diffraction Study of Uranium Speciation in Contaminated Vadose Zone Sediments from the Hanford Site, Washington State. Environ. Sci. Technol. 38, 2822-2828.

Chakraborty S., Favre F., Banerjee D., Scheinost A. C., Mullet M., Ehrhardt J.-J., Brendle J., Vidal L. and Charlet L. (2010) U(VI) Sorption and Reduction by Fe(II) Sorbed on Montmorillonite. Environ. Sci. Technol. 44, 3779-3785.

DOE (1997) Linking Legacies: Connecting the Cold War Nuclear Weapons Production Processes To Their Environmental Consequences, US Department of Energy.

Du X., Boonchayaanant B., Wu W.-M., Fendorf S., Bargar J. and Criddle C. S. (2011) Reduction of Uranium(VI) by Soluble Iron(II) Conforms with Thermodynamic Predictions. Environ. Sci. Technol. 45, 4718-4725.

Duff M., Coughlin J. and Hunter D. (2002) Uranium co-precipitation with iron oxide minerals. Geochimica et Cosmochimica Acta 66, 3533-3547. 
Farges F., Ponader C. W., Calas G. and Brown G. E. Jr. (1992) Structural environments of incompatible elements in silicate glass/melt systems: II. U(IV), U(V), and U(VI). Geochimica et Cosmochimica Acta 56, 4205-4220.

Finch R. and Murakami T. (1999) Systematics and paragenesis of uranium minerals. Reviews in Mineralogy and Geochemistry 38, 91-179.

Giammar D. and Hering J. (2001) Time Scales for Sorption-Desorption and Surface Precipitation of Uranyl on Goethite. Environ. Sci. Technol. 35, 3332-3337.

Gómez P., Garralón A., Buil B., Turrero M. J., Sánchez L. and la Cruz de B. (2006) Modeling of geochemical processes related to uranium mobilization in the groundwater of a uranium mine. Science of The Total Environment 366, 295-309.

Gu B., Brooks S. C., Roh Y. and Jardine P. M. (2003) Geochemical reactions and dynamics during titration of a contaminated groundwater with high uranium, aluminum, and calcium. Geochimica et Cosmochimica Acta 67, 2749-2761.

Hansel C. M., Benner S. G. and Fendorf S. (2005) Competing Fe(II)-Induced Mineralization Pathways of Ferrihydrite. Environ. Sci. Technol. 39, 7147-7153.

Hansel C., Benner S., Neiss J., Dohnalkova A., Kukkadapu R. and Fendorf S. (2003) Secondary mineralization pathways induced by dissimilatory iron reduction of ferrihydrite under advective flow. Geochimica et Cosmochimica Acta 67, 2977-2992.

Herbel M. and Fendorf S. (2006) Biogeochemical processes controlling the speciation and transport of arsenic within iron coated sands. Chem. Geol. 228, 16-32.

Hiemstra T., Van Riemsdijk W. H., Rossberg A. and Ulrich K.-U. (2009) A surface structural model for ferrihydrite II: Adsorption of uranyl and carbonate. Geochimica et Cosmochimica Acta 73, 4437-4451.

Hua B. and Deng B. (2008) Reductive Immobilization of Uranium(VI) by Amorphous Iron Sulfide. Environ. Sci. Technol. 42, 8703-8708.

Hua B., Xu H., Terry J. and Deng B. (2006) Kinetics of uranium(VI) reduction by hydrogen sulfide in anoxic aqueous systems. Environ. Sci. Technol. 40, 4666-4671.

Hyun S. P., Davis J. A., Sun K. and Hayes K. F. (2012) Uranium(VI) Reduction by Iron(II) Monosulfide Mackinawite. Environ. Sci. Technol. 46, 3369-3376.

IAEA (2004) The long term stabilization of uranium mill tailings, International Atomic Energy Agency.

Ilton E. S. and Bagus P. S. (2011) XPS determination of uranium oxidation states. Surf. Interface Anal. 43, 1549-1560.

Ilton E. S., Boily J.-F., Buck E. C., Skomurski F. N., Rosso K. M., Cahill C. L., Bargar J. R. and 
Felmy A. R. (2010) Influence of Dynamical Conditions on the Reduction of U(VI) at the Magnetite-Solution Interface. Environ. Sci. Technol. 44, 170-176.

Ilton E. S., Haiduc A., Cahill C. L. and Felmy A. R. (2005) Mica Surfaces Stabilize Pentavalent Uranium. Inorg. Chem. 44, 2986-2988.

Ilton E. S., Pacheco J. S. L., Bargar J. R., Shi Z., Liu J., Kovarik L., Engelhard M. H. and Felmy A. R. (2012) Reduction of U(VI) Incorporated in the Structure of Hematite. Environ. Sci. Technol. 46, 9428-9436.

Jones A. M., Collins R. N., Rose J. and Waite T. D. (2009) The effect of silica and natural organic matter on the $\mathrm{Fe}(\mathrm{II})$-catalysed transformation and reactivity of $\mathrm{Fe}(\mathrm{III})$ minerals. Geochimica et Cosmochimica Acta 73, 4409-4422.

Kerisit S., Felmy A. R. and Ilton E. S. (2011) Atomistic Simulations of Uranium Incorporation into Iron (Hydr)Oxides. Environ. Sci. Technol. 45, 2770-2776.

Larsen O. and Postma D. (2001) Kinetics of reductive bulk dissolution of lepidocrocite, ferrihydrite, and goethite. Geochimica et Cosmochimica Acta 65, 1367-1379.

Larson A. C. and Von Dreele R. B. (2000) GSAS, Los Alamos National Laboratory.

Latta D. E., Boyanov M. I., Kemner K. M., O'Loughlin E. J. and Scherer M. M. (2012a) Abiotic reduction of uranium by $\mathrm{Fe}(\mathrm{II})$ in soil. Applied Geochemistry 27, 1512-1524.

Latta D. E., Gorski C. A., Boyanov M. I., O'Loughlin E. J., Kemner K. M. and Scherer M. M. (2012b) Influence of Magnetite Stoichiometry on UVI Reduction. Environ. Sci. Technol. 46, $778-786$.

Liger E., Charlet L. and Van Cappellen P. (1999) Surface catalysis of uranium(VI) reduction by iron(II). Geochimica et Cosmochimica Acta 63, 2939-2955.

Lovley D. R. and Phillips E. J. (1992a) Reduction of uranium by Desulfovibrio desulfuricans. Appl. Environ. Microbiol. 58, 850-856.

Lovley D. R. and Phillips E. J. P. (1992b) Bioremediation of uranium contamination with enzymatic uranium reduction. Environ. Sci. Technol. 26, 2228-2234.

Marshall T.A., Morris K., Law G.T.W., Livens F.R., Mosselmans J.F.W., Bots P. and Shaw S. (2014) Incorporation of Uranium into Hematite during Crystallization from Ferrihydrite. Environ. Sci. Technol. 48, 3724-3731.

Neiss J., Stewart B. D., Nico P. S. and Fendorf S. (2007) Speciation-dependent microbial reduction of uranium within iron-coated sands. Environ. Sci. Technol. 41, 7343-7348.

Nico P. S., Stewart B. D. and Fendorf S. (2009) Incorporation of Oxidized Uranium into Fe (Hydr)oxides during Fe(II) Catalyzed Remineralization. Environ. Sci. Technol. 43, 73917396. 
Payne T. E. and Airey P. L. (2006) Radionuclide migration at the Koongarra uranium deposit, Northern Australia - Lessons from the Alligator Rivers analogue project. Physics and Chemistry of the Earth, Parts A/B/C 31, 572-586.

Payne T. E., Davis J. A. and Waite T. D. (1994) Uranium retention by weathered schists-the role of iron minerals. Radiochimica Acta 66, 297-303.

Pett-Ridge J. C., Monastra V. M., Derry L. A. and Chadwick O. A. (2007) Importance of atmospheric inputs and Fe-oxides in controlling soil uranium budgets and behavior along a Hawaiian chronosequence. Chem. Geol. 244, 691-707.

Postma D. (1993) The reactivity of iron oxides in sediments: A kinetic approach. Geochimica et Cosmochimica Acta 57, 5027-5034.

Ravel B. (2001) ATOMS: crystallography for the X-ray absorption spectroscopist. Journal of Synchrotron Radiation 8, 314-316.

Ravel B. and Newville M. (2005) ATHENA, ARTEMIS, HEPHAESTUS: data analysis for Xray absorption spectroscopy using IFEFFIT. Journal of Synchrotron Radiation 12, 537-541.

Riley R. and Zachara J. (1992) Chemical contaminants on DOE lands and selection of contaminant mixtures for subsurface science research.

Rossberg A., Ulrich K.-U., Weiss S., Tsushima S., Hiemstra T. and Scheinost A. C. (2009) Identification of Uranyl Surface Complexes on Ferrihydrite: Advanced EXAFS Data Analysis and CD-MUSIC Modeling. Environ. Sci. Technol. 43, 1400-1406.

Sato T., Murakami T., Yanase N., Isobe H., Payne T. E. and Airey P. L. (1997) Iron Nodules Scavenging Uranium from Groundwater. Environ. Sci. Technol. 31, 2854-2858.

Senko J. M., Suflita J. M. and Krumholz L. R. (2005) Geochemical Controls on Microbial Nitrate-Dependent U(IV) Oxidation. Geomicrobiology Journal 22, 371-378.

Sheng L., Szymanowski J. and Fein J. B. (2011) The effects of uranium speciation on the rate of U(VI) reduction by Shewanella oneidensis MR-1. Geochimica et Cosmochimica Acta 75, 3558-3567.

Singer D. M., Chatman S. M., Ilton E. S., Rosso K. M., Banfield J. F. and Waychunas G. A. (2012) U(VI) Sorption and Reduction Kinetics on the Magnetite (111) Surface. Environ. Sci. Technol. 46, 3821-3830.

Skomurski F. N., Ilton E. S., Engelhard M. H., Arey B. W. and Rosso K. M. (2011) Heterogeneous reduction of $\mathrm{U}^{6+}$ by structural $\mathrm{Fe}^{2+}$ from theory and experiment. Geochimica et Cosmochimica Acta 75, 7277-7290.

Smith S. C., Douglas M., Moore D. A., Kukkadapu R. K. and Arey B. W. (2009) Uranium Extraction From Laboratory-Synthesized, Uranium-Doped Hydrous Ferric Oxides. Environ. Sci. Technol. 43, 2341-2347. 
Soderholm L., Skanthakumar S., Gorman-Lewis D., Jensen M. P. and Nagy K. L. (2008) Characterizing solution and solid-phase amorphous uranyl silicates. Geochimica et Cosmochimica Acta 72, 140-150.

Soldatov A. V., Lamoen D., Konstantinović M. J., Van den Berghe S., Scheinost A. C. and Verwerft M. (2007) Local structure and oxidation state of uranium in some ternary oxides: X-ray absorption analysis. Journal of Solid State Chemistry 180, 54-61.

Stewart B. D., Mayes M. A. and Fendorf S. (2010) Impact of Uranyl-Calcium-Carbonato Complexes on Uranium(VI) Adsorption to Synthetic and Natural Sediments. Environ. Sci. Technol. 44, 928-934.

Stewart B. D., Nico P. S. and Fendorf S. (2009) Stability of Uranium Incorporated into Fe (Hydr)oxides under Fluctuating Redox Conditions. Environ. Sci. Technol. 43, 4922-4927.

Stewart B., Neiss J. and Fendorf S. (2007) Quantifying Constraints Imposed by Calcium and Iron on Bacterial Reduction of Uranium(VI). J. Environ. Qual. 36, 363-372.

Stookey L. (1970) Ferrozine-a new spectrophotometric reagent for iron. Analytical Chemistry 42, 779-781.

Stubbs J. E., Elbert D. C., Veblen D. R. and Zhu C. (2006) Electron Microbeam Investigation of Uranium-Contaminated Soils from Oak Ridge, TN, USA. Environ. Sci. Technol. 40, 21082113.

Stubbs J. E., Veblen L. A., Elbert D. C., Zachara J. M., Davis J. A. and Veblen D. R. (2009) Newly recognized hosts for uranium in the Hanford Site vadose zone. Geochimica et Cosmochimica Acta 73, 1563-1576.

Suzuki Y., Kelly S., Kemner K. and Banfield J. (2002) Radionuclide contamination Nanometre-size products of uranium bioreduction. Nature 419, 134-134.

Toby B. (2001) EXPGUI, a graphical user interface for GSAS. J. Appl. Crystallogr. 34, 210213.

Waite T. D., Davis J. A., Payne T. E., Waychunas G. A. and Xu N. (1994) Uranium(VI) adsorption to ferrihydrite: Application of a surface complexation model. Geochimica et Cosmochimica Acta 58, 5465-5478.

Wander M. C. F. and Shuford K. L. (2012) A theoretical study of the qualitative reaction mechanism for the homogeneous disproportionation of pentavalent uranyl ions. Geochimica et Cosmochimica Acta 84, 177-185.

Wander M. C. F., Kerisit S., Rosso K. M. and Schoonen M. A. A. (2006) Kinetics of Triscarbonato Uranyl Reduction by Aqueous Ferrous Iron: A Theoretical Study. J. Phys. Chem. A 110, 9691-9701.

Wang Z., Zachara J. M., Gassman P. L., Liu C., Qafoku O., Yantasee W. and Catalano J. G. 
(2005) Fluorescence spectroscopy of U(VI)-silicates and U(VI)-contaminated Hanford sediment. Geochimica et Cosmochimica Acta 69, 1391-1403.

Webb S. M. (2005) SIXPack a Graphical User Interface for XAS Analysis Using IFEFFIT. Physica Scripta, 1011.

Wilkins M. J., Livens F. R., Vaughan D. J. and Lloyd J. R. (2006) The Impact of Fe(III)reducing Bacteria on Uranium Mobility. Biogeochemistry 78, 125-150.

Wu W.-M., Carley J., Gentry T., Ginder-Vogel M., Fienen M., Mehlhorn T., Yan H., Caroll S., Pace M., Nyman J., Luo J., Gentile M., Fields M., Hickey R., Gu B., Watson D., Cirpka O., Zhou J., Fendorf S., Kitanidis P., Jardine P. and Criddle C. (2006) Pilot-Scale in Situ Bioremedation of Uranium in a Highly Contaminated Aquifer. 2. Reduction of U(VI) and Geochemical Control of U(VI) Bioavailability. Environ. Sci. Technol. 40, 3986-3995.

Yabusaki S. B., Fang Y., Long P. E., Resch C. T., Peacock A. D., Komlos J., Jaffe P. R., Morrison S. J., Dayvault R. D., White D. C. and Anderson R. T. (2007) Uranium removal from groundwater via in situ biostimulation: Field-scale modeling of transport and biological processes. J. Contam. Hydrol. 93, 216-235.

Yang L., Steefel C. I., Marcus M. A. and Bargar J. R. (2010) Kinetics of Fe(II)-Catalyzed Transformation of 6-line Ferrihydrite under Anaerobic Flow Conditions. Environ. Sci. Technol. 44, 5469-5475. 


\section{Tables}

Table 1. X-ray photoelectron spectroscopy fitting percentages for the $U 4 f_{5 / 2}$ and $4 f_{7 / 2}$ primary and satellite peaks. Solids were from ferrihydrite slurry reacted with $10 \mu \mathrm{M} \mathrm{U}$ or $100 \mu \mathrm{M} \mathrm{U}, 0 \mathrm{mM} \mathrm{Ca}$ or $4 \mathrm{mM} \mathrm{Ca}, 3.8 \mathrm{mM}$ carbonate, and $0.3 \mathrm{mM} \mathrm{Fe}(\mathrm{II})$, at pH 7.0.

Uncertainty estimates are expressed as one standard deviation of replicate measurements of three separate points of XPS analysis.

\begin{tabular}{ccccc}
\hline $\begin{array}{c}\mathrm{U} \text { concentration } \\
(\mu \mathrm{M})\end{array}$ & $\begin{array}{c}\text { Ca concentration } \\
(\mathrm{mM})\end{array}$ & $\mathrm{U}(\mathrm{IV}), \%$ & $\mathrm{U}(\mathrm{V}), \%$ & $\mathrm{U}(\mathrm{VI}), \%$ \\
\hline 10 & 0 & $21.6 \pm 2.1$ & $55.6 \pm 3.6$ & $22.8 \pm 1.4$ \\
100 & 0 & $28.8 \pm 0.5$ & $60.6 \pm 0.7$ & $10.6 \pm 1.1$ \\
10 & 4 & $23.0 \pm 1.7$ & $51.2 \pm 1.3$ & $25.8 \pm 2.5$ \\
100 & 4 & $25.9 \pm 2.1$ & $51.1 \pm 1.2$ & $23.0 \pm 2.0$ \\
\hline
\end{tabular}




\section{Figures}

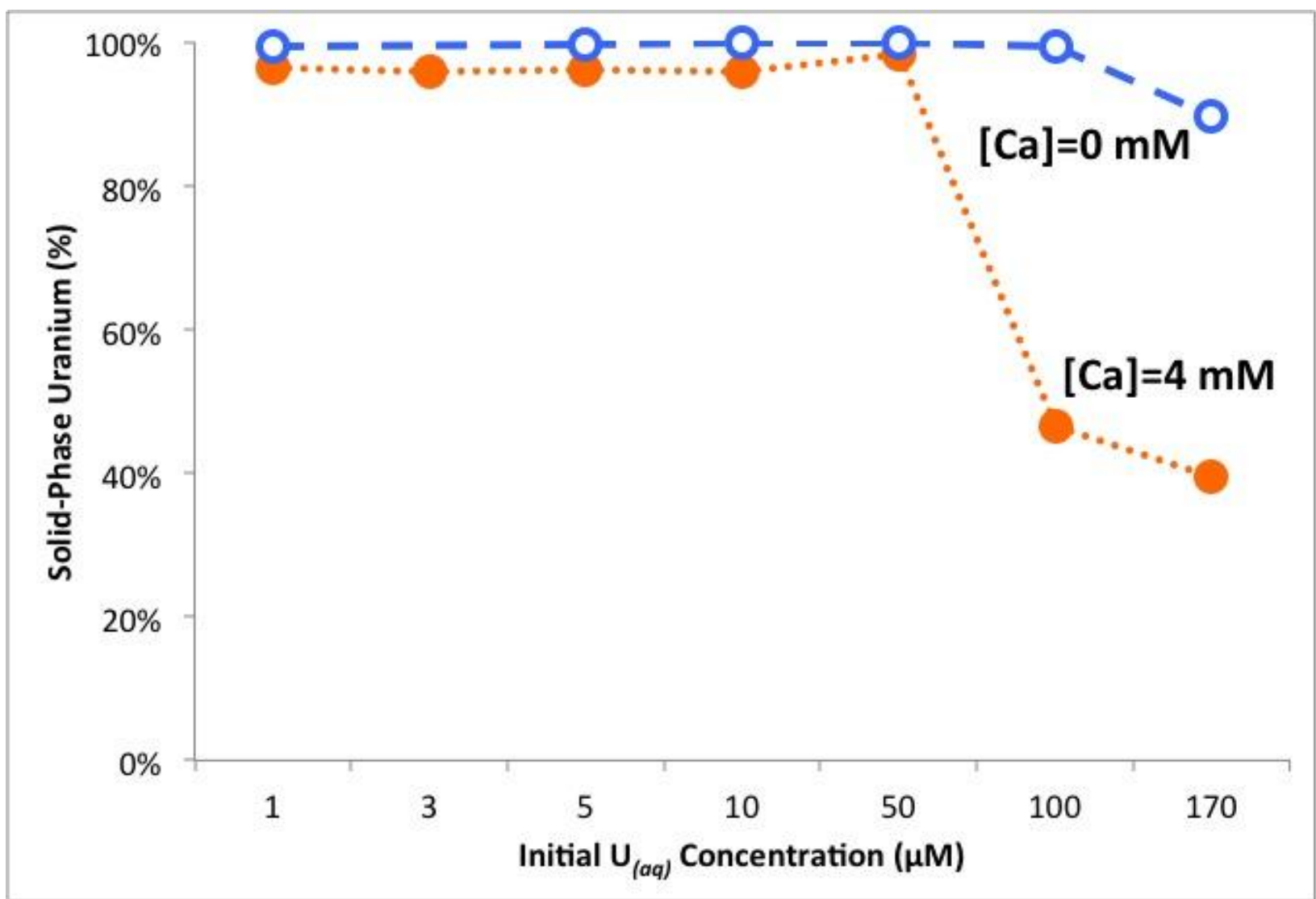

Figure 1. Uranium partitioned into the solid phase as a function of U(VI) $)_{(a q)}$ concentration $\left(\left[\mathrm{U}_{\text {initial }}\right]=1\right.$ to $\left.170 \mu \mathrm{M}\right)$ and $\mathrm{Ca}^{2+}{ }_{(a q)}$ concentration $(0 \mathrm{mM}$ or $4 \mathrm{mM} \mathrm{Ca})$ upon reaction with ferrihydrite, $0.3 \mathrm{mM} \mathrm{Fe}(\mathrm{II})$, and $3.8 \mathrm{mM}$ carbonate at a $\mathrm{pH}$ of 7.0. Error bars are smaller than the symbols used to represent the data and are not displayed. 


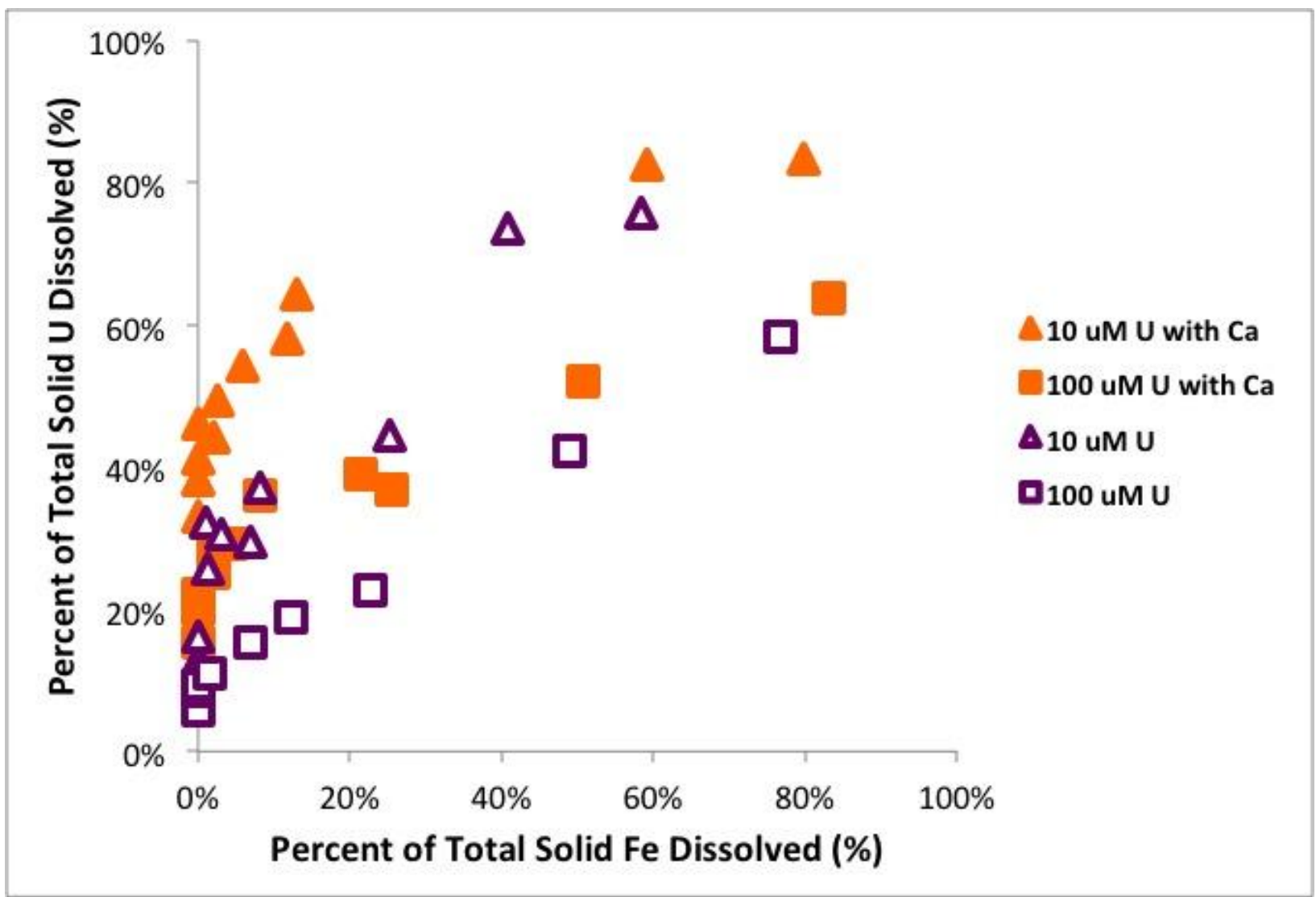

Figure 2. Uranium and Fe release from U-bearing iron oxide solids upon reaction with 10 $\mathrm{mM}$ ascorbic acid at $\mathrm{pH} 3.0$ for 18 days. Solids were obtained from reacting ferrihydrite with $10 \mu \mathrm{M} U$ and $100 \mu \mathrm{M} \mathrm{U}, 0.3 \mathrm{mM} \mathrm{Fe}(\mathrm{II}), 3.8 \mathrm{mM}$ carbonate, and $0 \mathrm{mM} \mathrm{Ca}$ or $4 \mathrm{mM}$ $\mathrm{Ca}$, at $\mathrm{pH} 7.0$. 


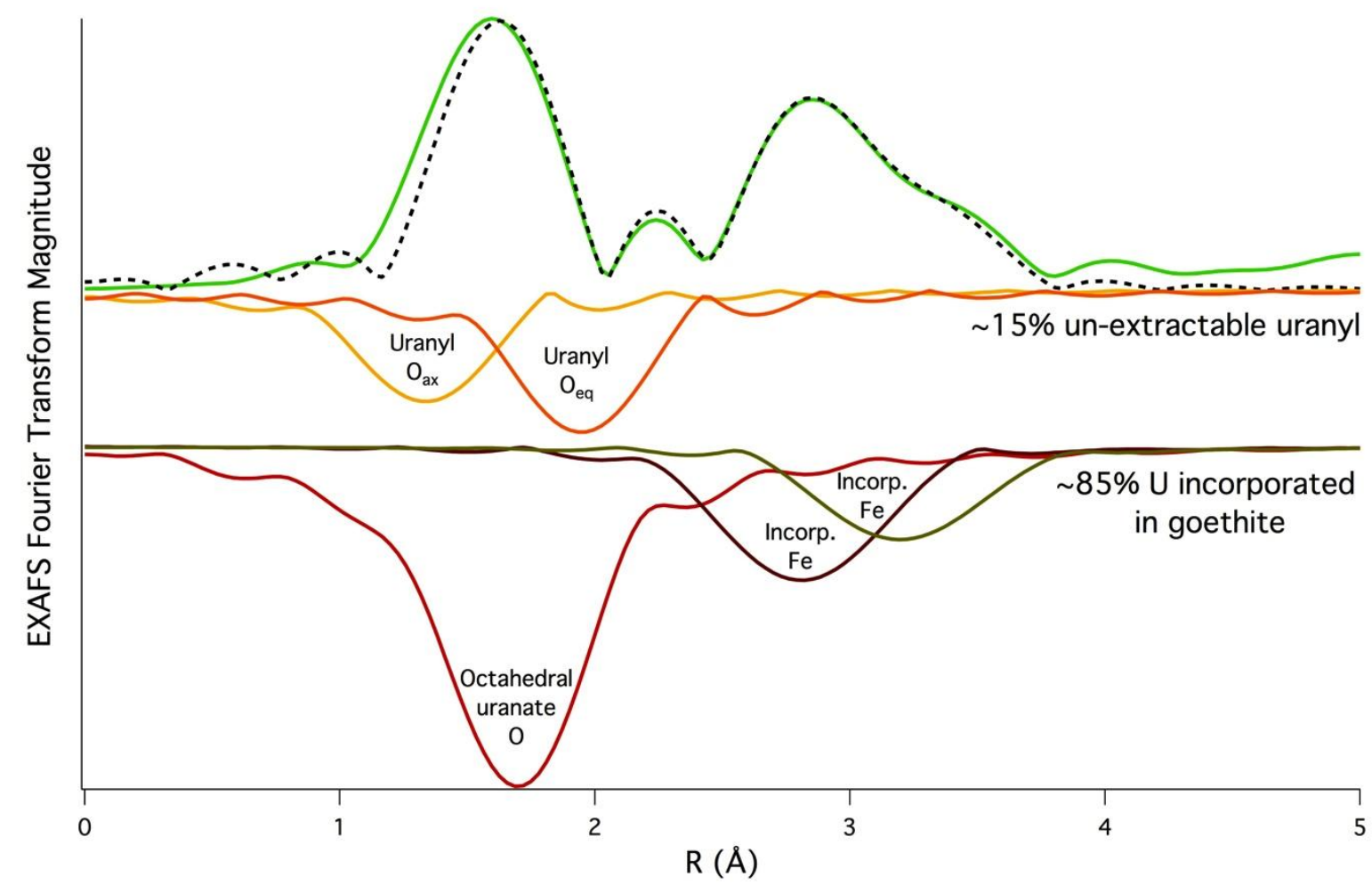

Figure 3. Uranium $\mathrm{L}_{3}$-edge EXAFS shell-by-shell fit of incorporated $\mathrm{U}$ resulting from the reaction of ferrihydrite with $1 \mu \mathrm{M} \mathrm{U}, 0.3 \mathrm{mM} \mathrm{Fe}(\mathrm{II})$, and $3.8 \mathrm{mM}$ bicarbonate, at $\mathrm{pH}$ 7.0. Solids underwent bicarbonate extraction to remove adsorbed U(VI). The fits illustrate $\sim 15 \%$ un-extracted $\mathrm{U}(\mathrm{VI})$ and $\sim 85 \% \mathrm{U}$ incorporated into goethite. The solid green line is the data, the dotted black line represents the overall fit, and the inverted solid lines are the individual paths (U-O and $\mathrm{U}-\mathrm{Fe}$ ) that make up the overall fit. 


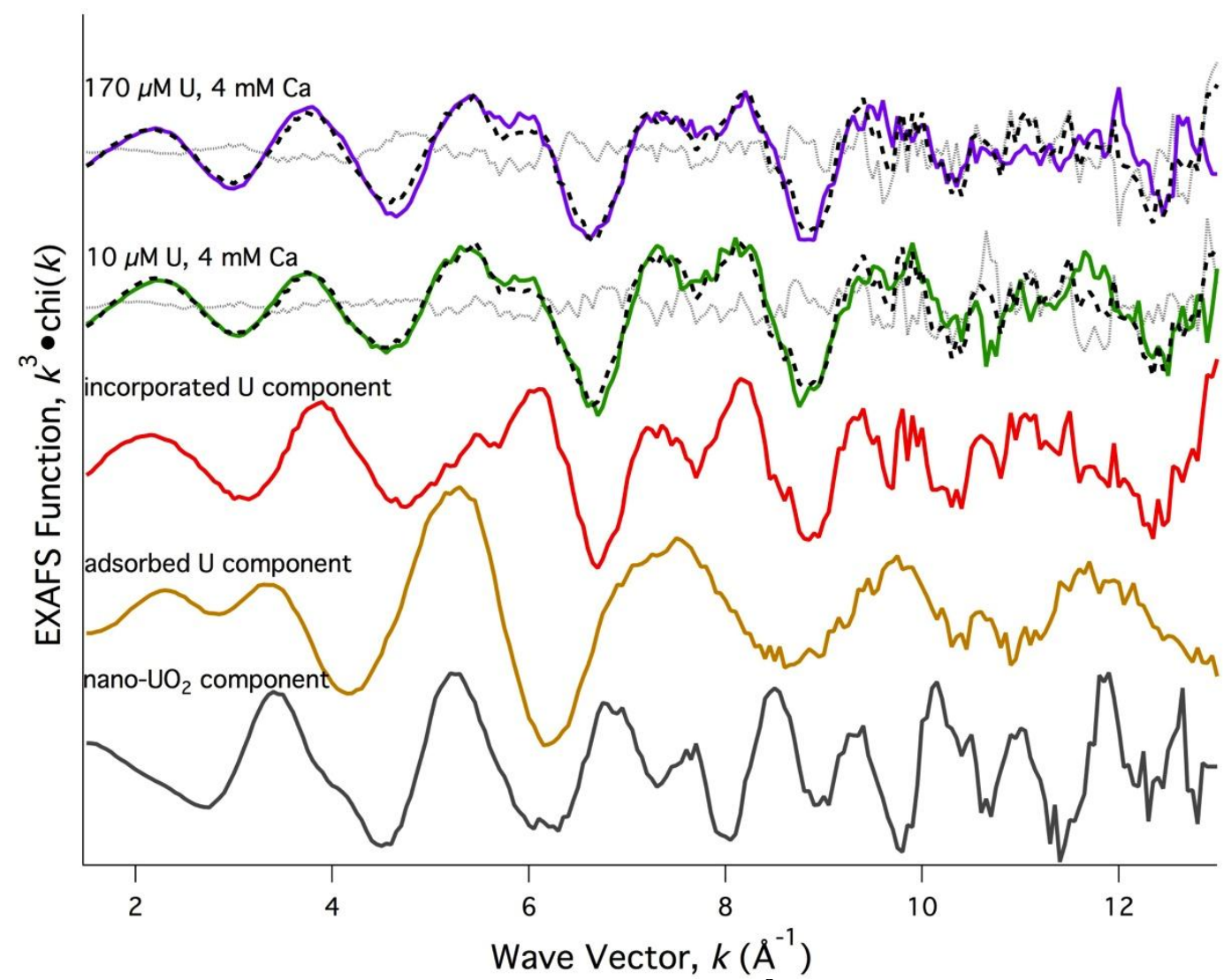

Figure 4. EXAFS linear combination fitting results for $k^{3}$-weighted $\mathrm{U} \mathrm{L}_{3}$-edge EXAFS spectra for ferrihydrite reacted with U(VI), $0.3 \mathrm{mM} \mathrm{Fe(II),} 3.8 \mathrm{mM}$ carbonate, and $4 \mathrm{mM}$ $\mathrm{Ca}$, at $\mathrm{pH}$ 7.0. Data (colored lines), fitting components (incorporated $\mathrm{U}$, adsorbed $\mathrm{U}$, nano- $\mathrm{UO}_{2}$ ), linear combination fits (black dotted lines), and residuals (light grey dotted lines) are shown. 

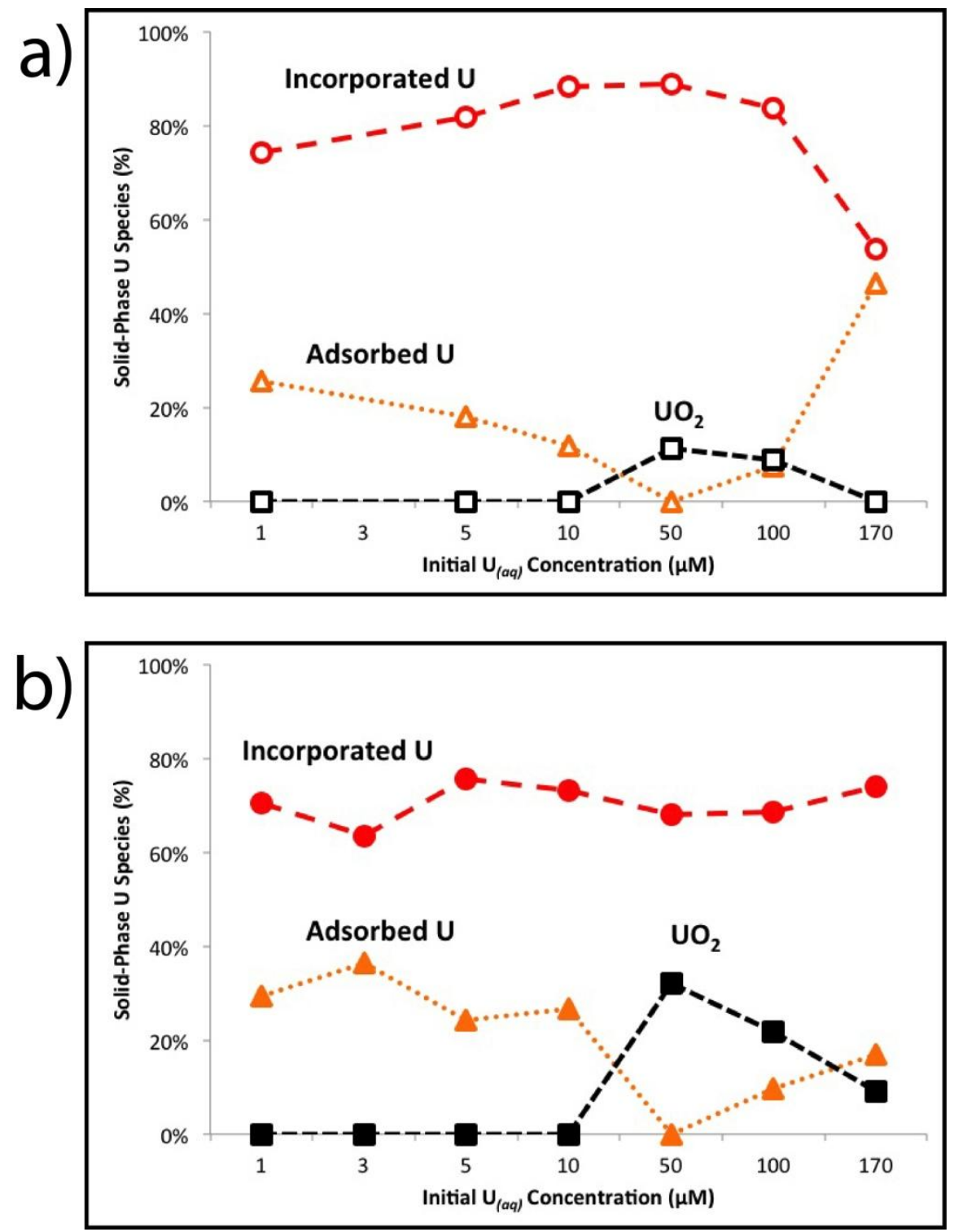

Figure 5. Solid phase $\mathrm{U}$ speciation from EXAFS linear combination fits, as a function of initial $\mathrm{U}(\mathrm{VI})_{(a q)}$ concentration $\left(\left[\mathrm{U}_{\text {initial }}\right]=1\right.$ to $\left.170 \mu \mathrm{M}\right)$ after reaction with ferrihydrite, 0.3 $\mathrm{mM} \mathrm{Fe}(\mathrm{II}), 3.8 \mathrm{mM}$ carbonate, and (a) $0 \mathrm{mM} \mathrm{Ca}$, or (b) $4 \mathrm{mM} \mathrm{Ca}$, at pH 7.0. Uranium incorporated into goethite dominates solid phase $\mathrm{U}$ over this range of reaction conditions. Linear combination fitting EXAFS percentages are shown for each component: incorporated $\mathrm{U}$ (red circles), adsorbed $\mathrm{U}$ (yellow triangles), and $\mathrm{UO}_{2}$ (black squares). 
a)

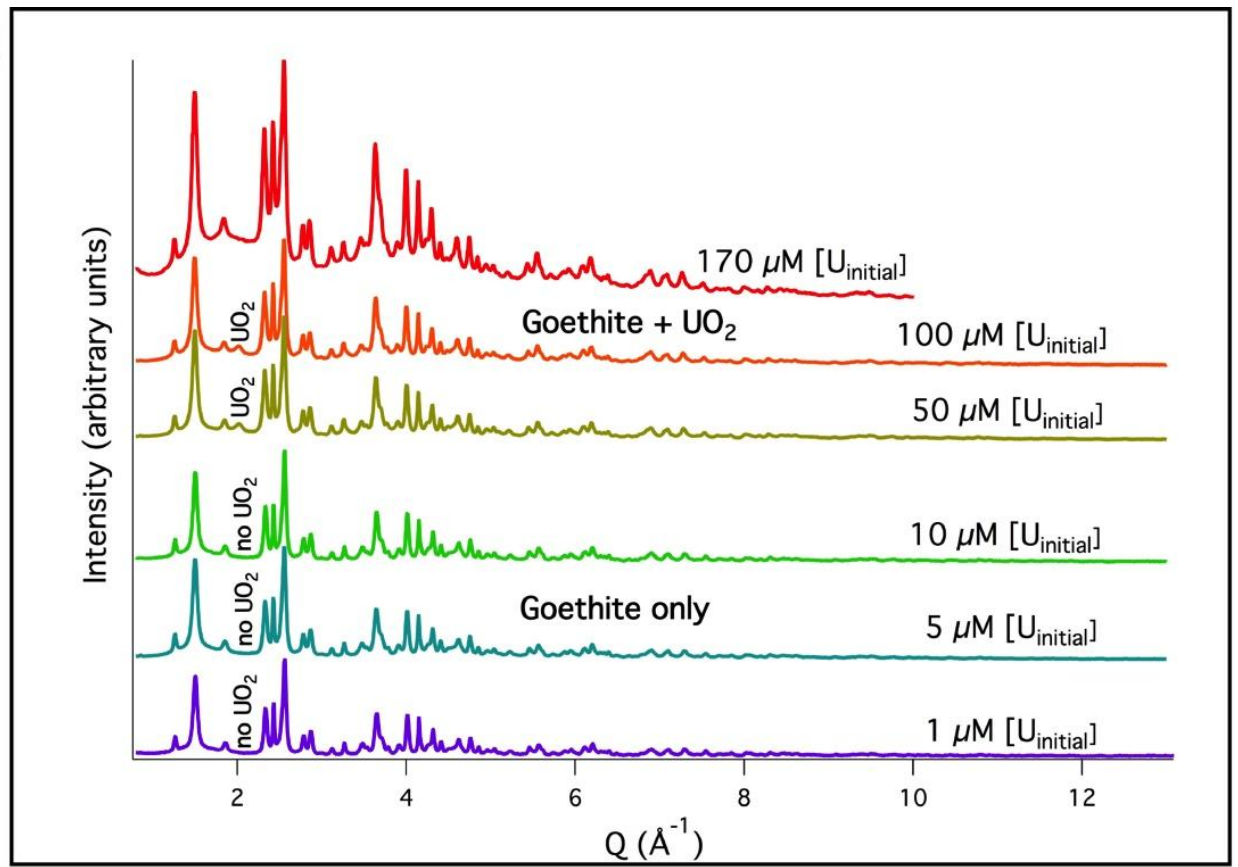

b)

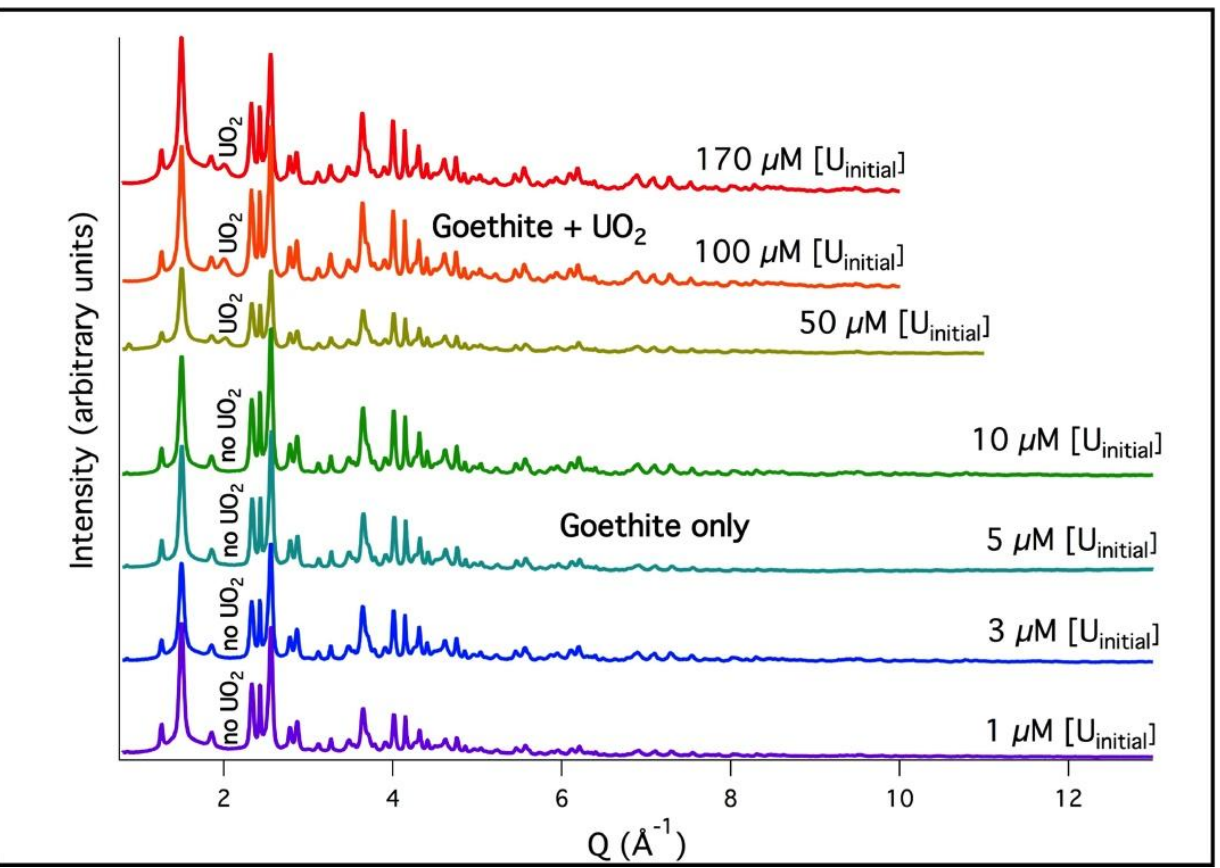

Figure 6. Crystalline solid phases identified with high-resolution powder diffraction, resulting from $\mathrm{U}(\mathrm{VI})\left(\left[\mathrm{U}_{\text {initial }}\right]=1\right.$ to $\left.170 \mu \mathrm{M}\right)$ reacted with $0.3 \mathrm{mM} \mathrm{Fe}(\mathrm{II}), 3.8 \mathrm{mM}$ carbonate, and (a) $0 \mathrm{mM} \mathrm{Ca}$ or (b) $4 \mathrm{mM} \mathrm{Ca}$, at $\mathrm{pH}$ 7.0. 


\section{Iron oxide with U}

\section{$5 \mathrm{~nm}$}

Figure 7. Transmission electron microscope image of solids resulting from $100 \mu \mathrm{M}$ [ $\left.\mathrm{U}_{\text {initial }}\right]$ reacted with $4 \mathrm{mM} \mathrm{Ca}$ and $0.3 \mathrm{mM} \mathrm{Fe}(\mathrm{II})$, at $\mathrm{pH}$ 7.0. Energy-dispersive $\mathrm{x}$-ray spectroscopic analysis, coupled with measurements of lattice fringes for d-spacings, indicate that the particles are mixed iron oxides with $\mathrm{U}$ (upper right, labeled) and $\mathrm{UO}_{2}$ (center-left, circled and labeled). 


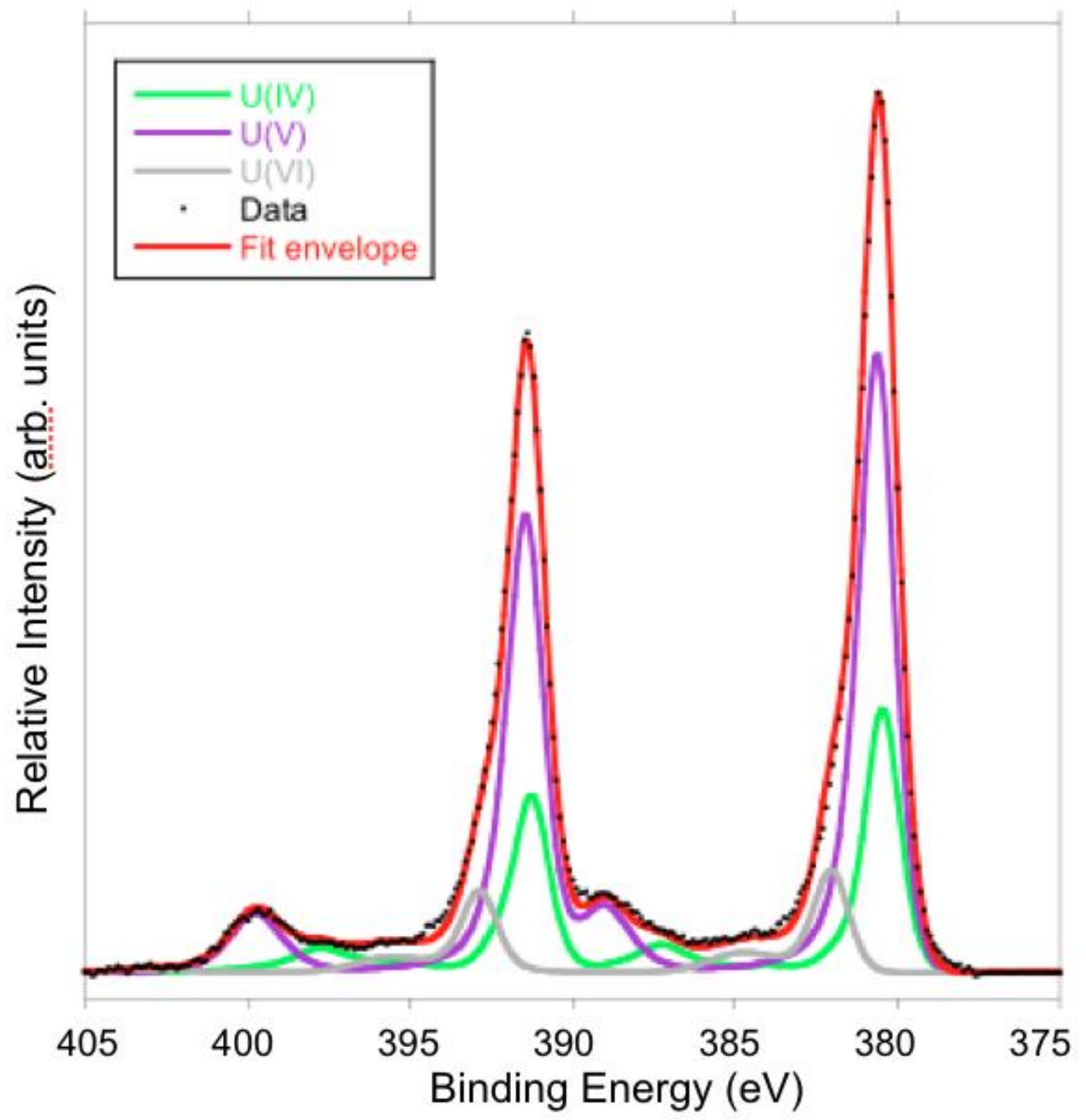

Figure 8. X-ray photoelectron spectrum of U-bearing goethite resulting from ferrihydrite reacted with $100 \mu \mathrm{M} \mathrm{U}$ and $0.3 \mathrm{mM} \mathrm{Fe}(\mathrm{II})$, at $\mathrm{pH}$ 7.0. Binding energy was referenced to adventitious $\mathrm{C} 1 \mathrm{~s}$ at $285.0 \mathrm{eV}$. The primary $\mathrm{U}_{4} \mathrm{f}_{5 / 2}$ peak and $\mathrm{U}_{4} \mathrm{f}_{7 / 2}$ peaks, along with satellite peaks, allow for quantification of $U(I V)$ in green, $U(V)$ in purple, and U(VI) in grey. The overall fit is shown in red. 


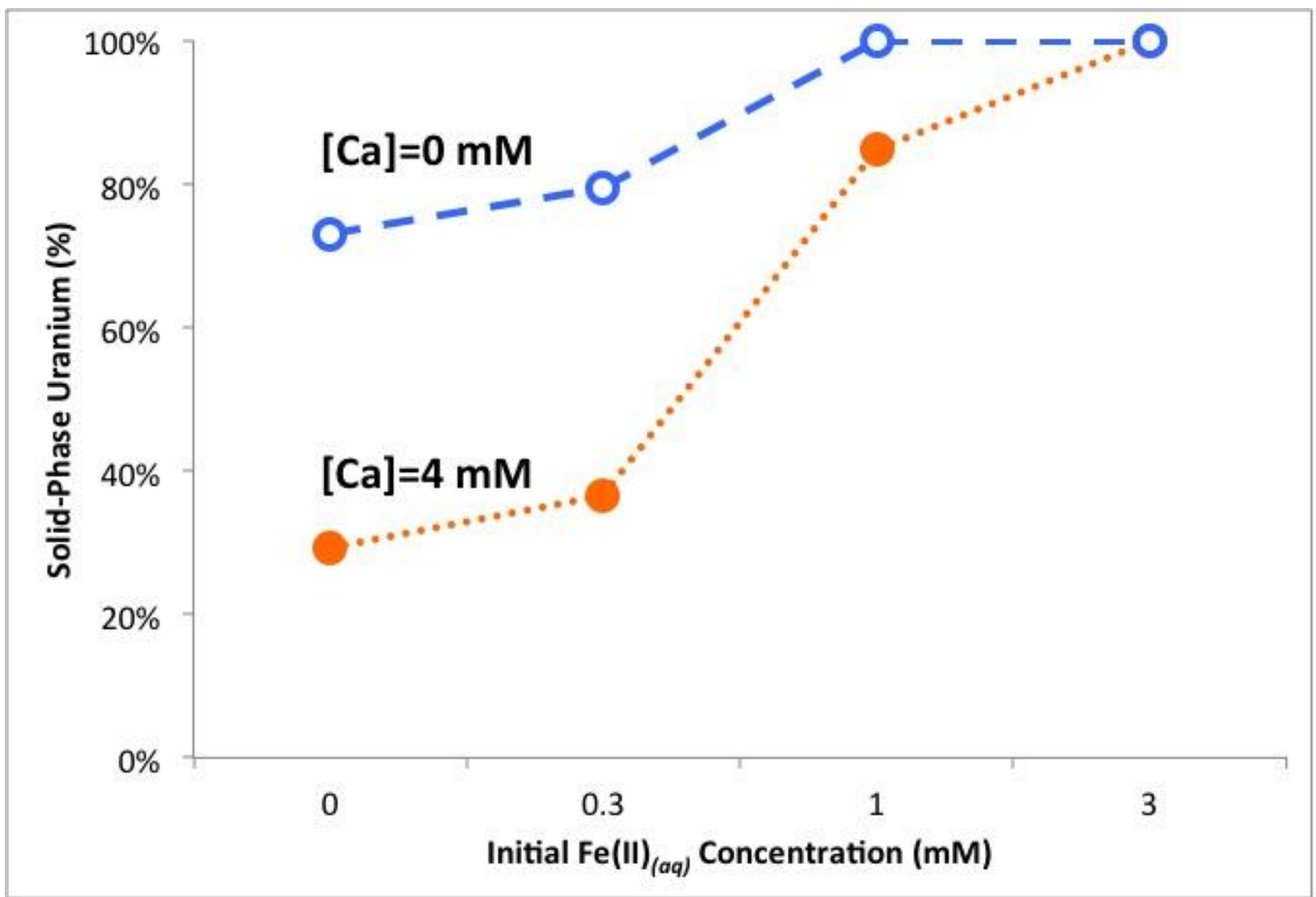

Figure 9. Uranium partitioned into the solid phase as a function of $\mathrm{Fe}(\mathrm{II})_{(a q)}$ concentration $\left(\left[\mathrm{Fe}(\mathrm{II})_{\text {initial }}\right]=0\right.$ to $\left.3 \mathrm{mM}\right)$ and $\mathrm{Ca}^{2+}{ }_{(a q)}$ concentration $(0 \mathrm{mM}$ or $4 \mathrm{mM} \mathrm{Ca})$ upon reaction with ferrihydrite, $127 \mu \mathrm{M} \mathrm{U}(\mathrm{VI})$, and $3.8 \mathrm{mM}$ carbonate at $\mathrm{pH}$ 7.0-7.5. Error bars are smaller than the symbols used to represent the data and are not displayed. 

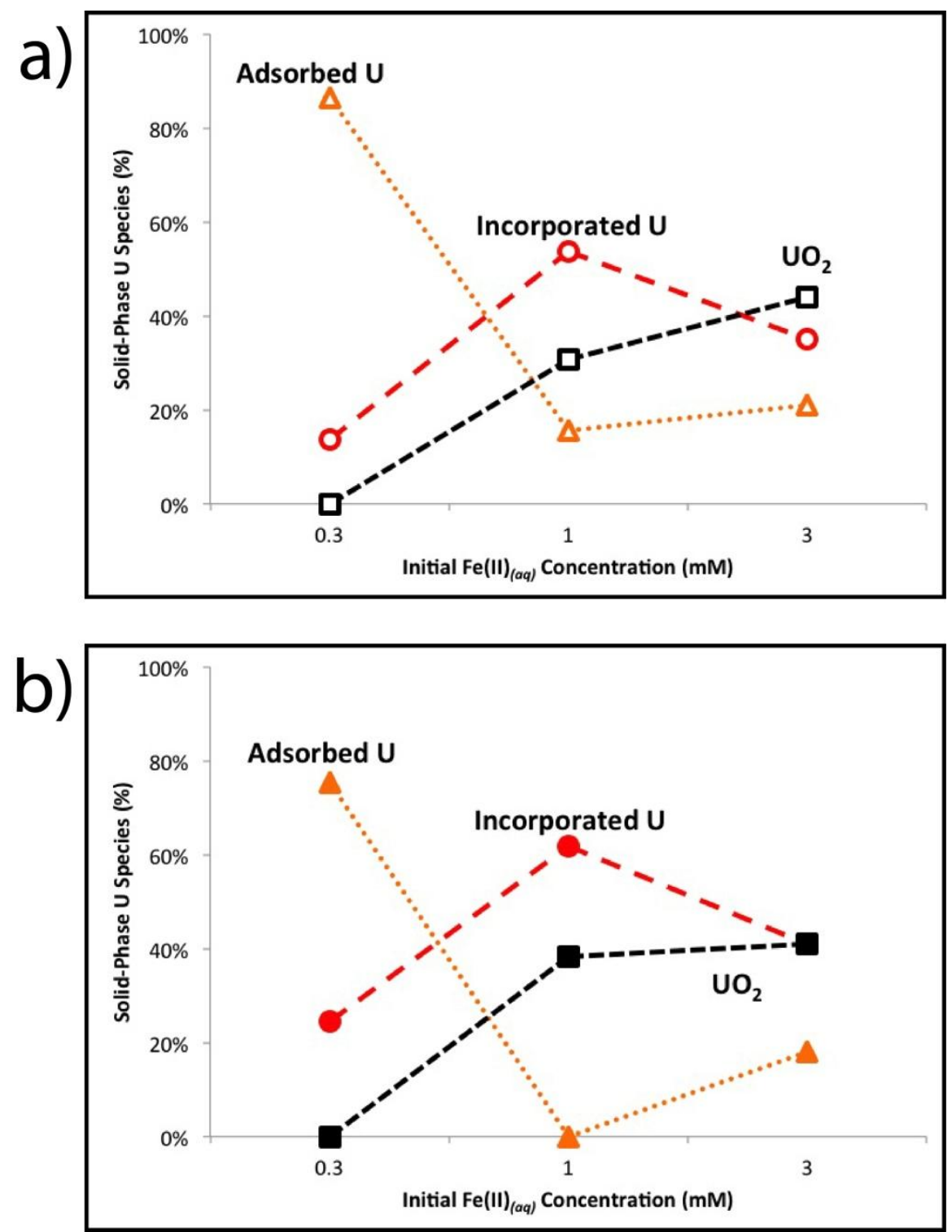

Figure 10. Solid phase U speciation from EXAFS linear combination fits, as a function of initial $\mathrm{Fe}(\mathrm{II})_{(a q)}$ concentration $\left(\left[\mathrm{Fe}(\mathrm{II})_{\text {initial }}\right]=0.3\right.$ to $\left.3 \mathrm{mM}\right)$ after reaction with ferrihydrite, $127 \mu \mathrm{M} \mathrm{U}(\mathrm{VI}), 3.8 \mathrm{mM}$ carbonate, and (a) $0 \mathrm{mM} \mathrm{Ca}$, or (b) $4 \mathrm{mM} \mathrm{Ca}$, at $\mathrm{pH}$ 7.0-7.5. Uranium incorporated into goethite is a common form of solid phase $\mathrm{U}$ over this range of reaction conditions. Linear combination fitting EXAFS percentages are shown for each component: incorporated $\mathrm{U}$ (red circles), adsorbed $\mathrm{U}$ (yellow triangles), and $\mathrm{UO}_{2}$ (black squares). 

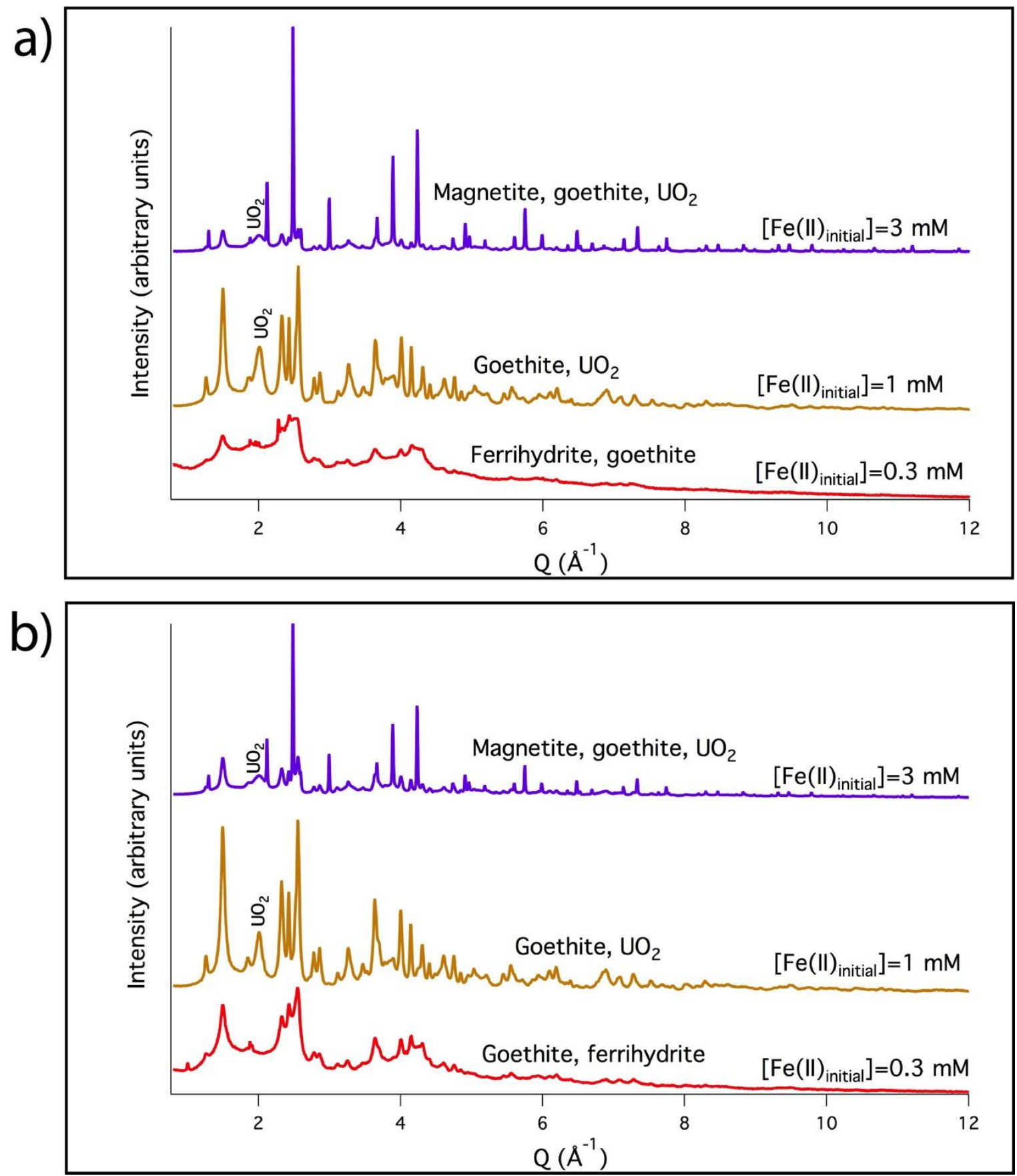

Figure 11. Crystalline solid phases identified with high-resolution powder diffraction, resulting from $\mathrm{Fe}(\mathrm{II})\left(\left[\mathrm{Fe}(\mathrm{II})_{\text {initial }}\right]=0.3\right.$ to $3 \mathrm{mM}$ ) reacted with $127 \mu \mathrm{M} \mathrm{U}(\mathrm{VI}), 3.8 \mathrm{mM}$ carbonate, and (a) $0 \mathrm{mM} \mathrm{Ca}$ or (b) $4 \mathrm{mM} \mathrm{Ca}$, at $\mathrm{pH}$ 7.0-7.5. 


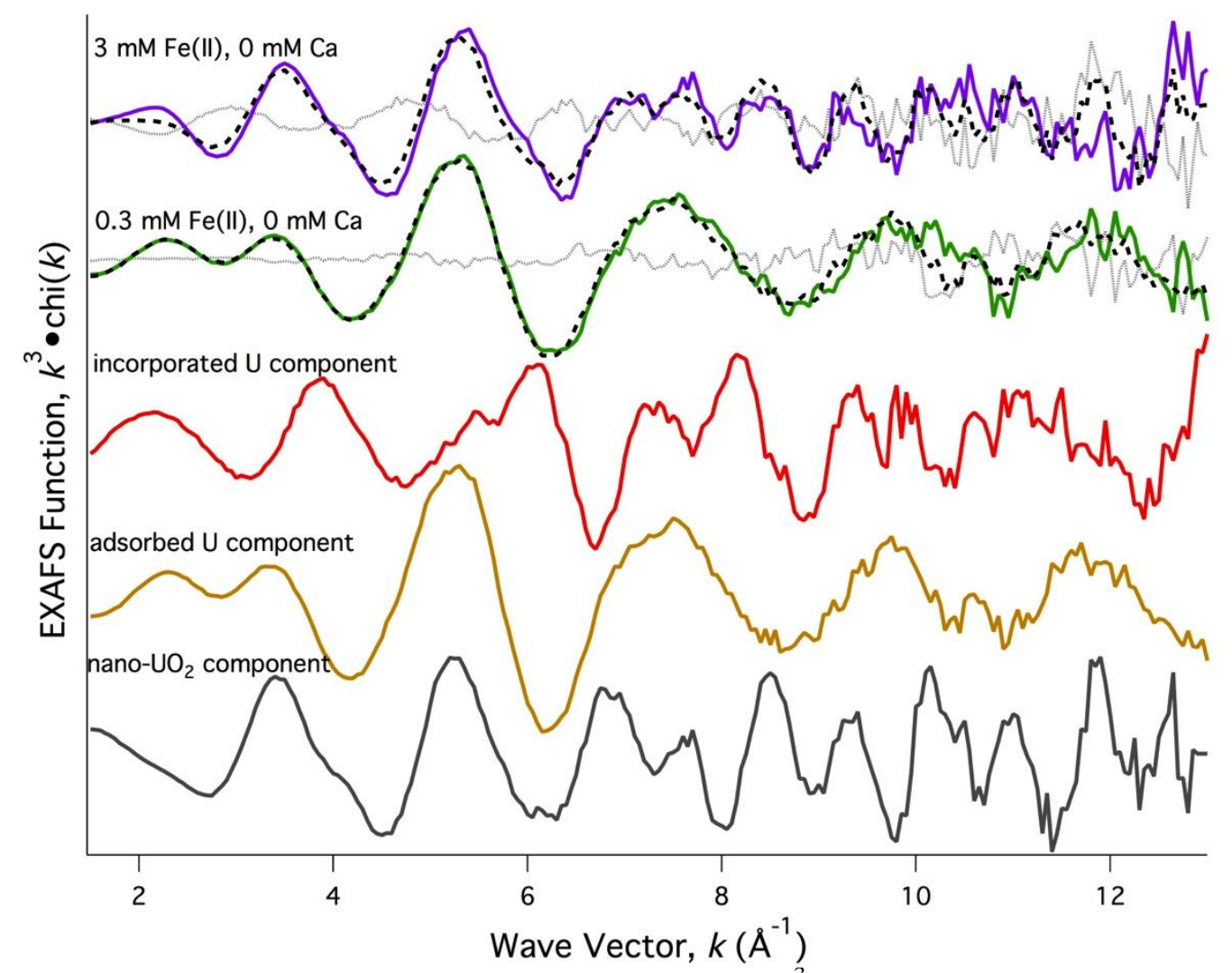

Figure 12. EXAFS linear combination fitting results for $k^{3}$-weighted $\mathrm{U} \mathrm{L}_{3}$-edge EXAFS spectra for ferrihydrite reacted with $127 \mu \mathrm{M} \mathrm{U}(\mathrm{VI}), 0.3-3 \mathrm{mM} \mathrm{Fe}(\mathrm{II}), 3.8 \mathrm{mM}$ carbonate, and $0 \mathrm{mM} \mathrm{Ca}$, at $\mathrm{pH}$ 7.0-7.5. Data (colored lines), fitting components (incorporated $\mathrm{U}$, adsorbed $\mathrm{U}$, nano- $\mathrm{UO}_{2}$ ), linear combination fits (black dotted lines), and residuals (light grey dotted lines) are shown. 


\section{Starting Materials}

\section{Reaction}

Conditions

\section{Favored Solid Phase Products}

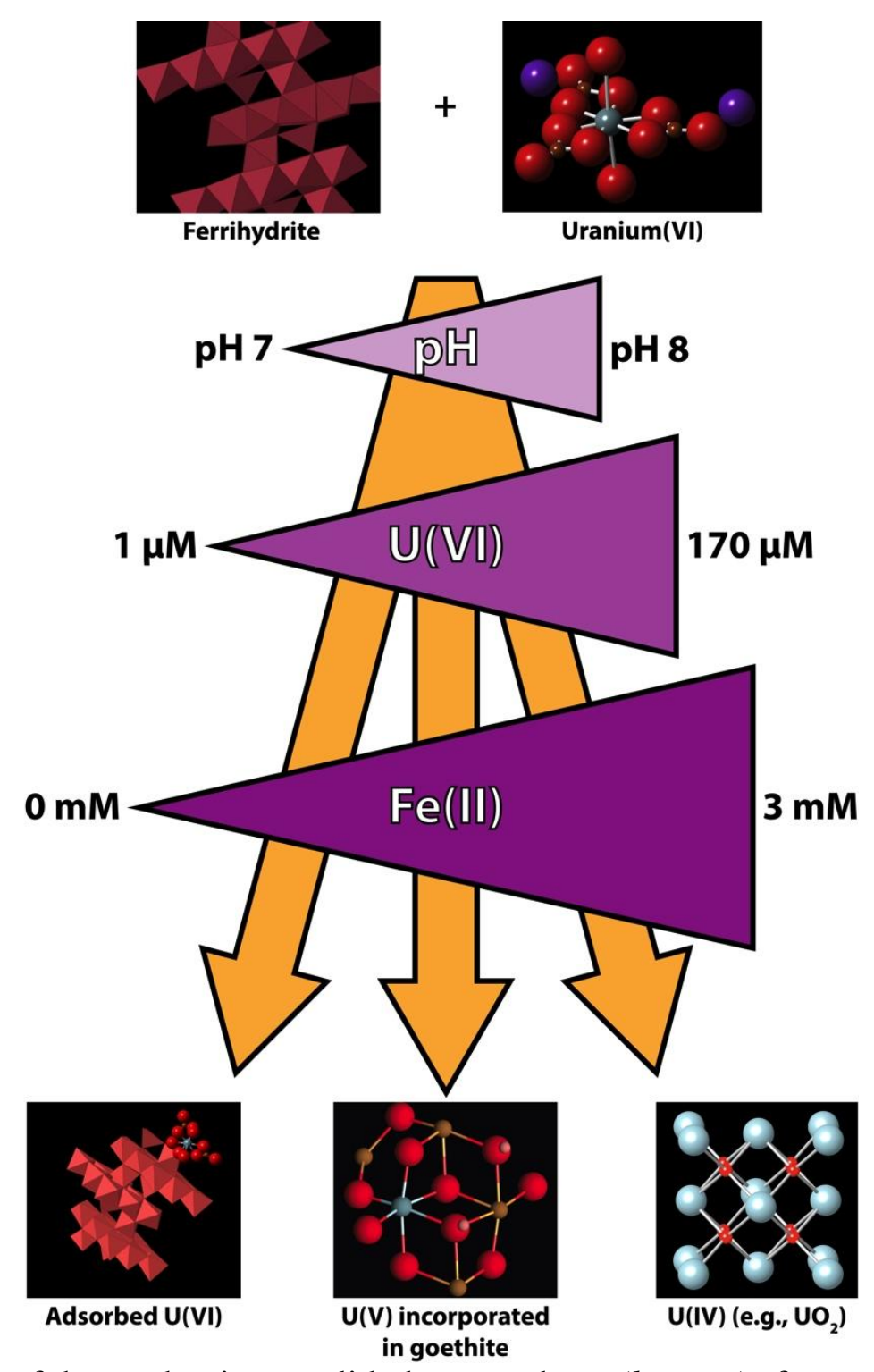

Figure 13. Conceptual model of the predominant solid phase products (bottom) of uranyl and ferrihydrite transformation (yellow arrows). Solid phase products are influenced primarily by $\mathrm{Fe}(\mathrm{II})$ concentration, $\mathrm{U}$ concentration, and initial $\mathrm{pH}$, with $\mathrm{Fe}(\mathrm{II})$ concentration exerting the dominant control (as indicated by the size and shading of the triangles). Higher $\mathrm{pH}, \mathrm{U}$ concentration, and $\mathrm{Fe}(\mathrm{II})$ concentration favor solid phase products toward the right of the diagram (incorporated $\mathrm{U}(\mathrm{V})$ and $\mathrm{U}(\mathrm{IV})$ precipitates). 


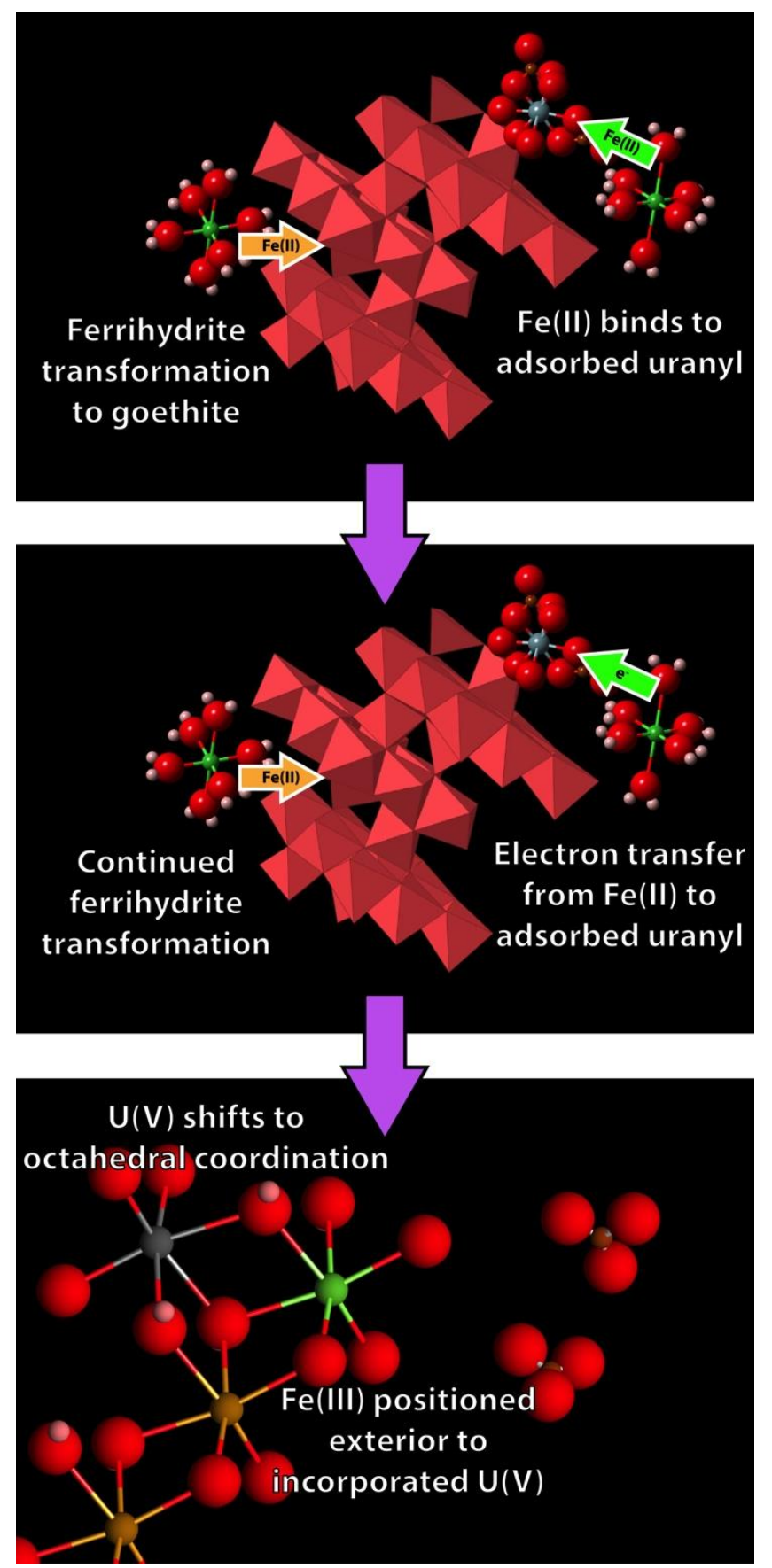

Figure 14. Uranium incorporation mechanism. The addition of Fe(II) drives ferrihydrite transformation to goethite, and Fe(II) binding to adsorbed uranyl initiates incorporation (top). Uranium(V) incorporation occurs via electron transfer from Fe(II) to U(VI)

(middle), creating a Fe(III) atom exterior to an incorporated $\mathrm{U}(\mathrm{V})$ (bottom), and enabling continued crystal growth of goethite. Uranium is grey, $\mathrm{Fe}(\mathrm{III})$ in the iron oxide is yellow, and $\mathrm{Fe}(\mathrm{II} / \mathrm{III})$ participating in the reaction is shown in green. 


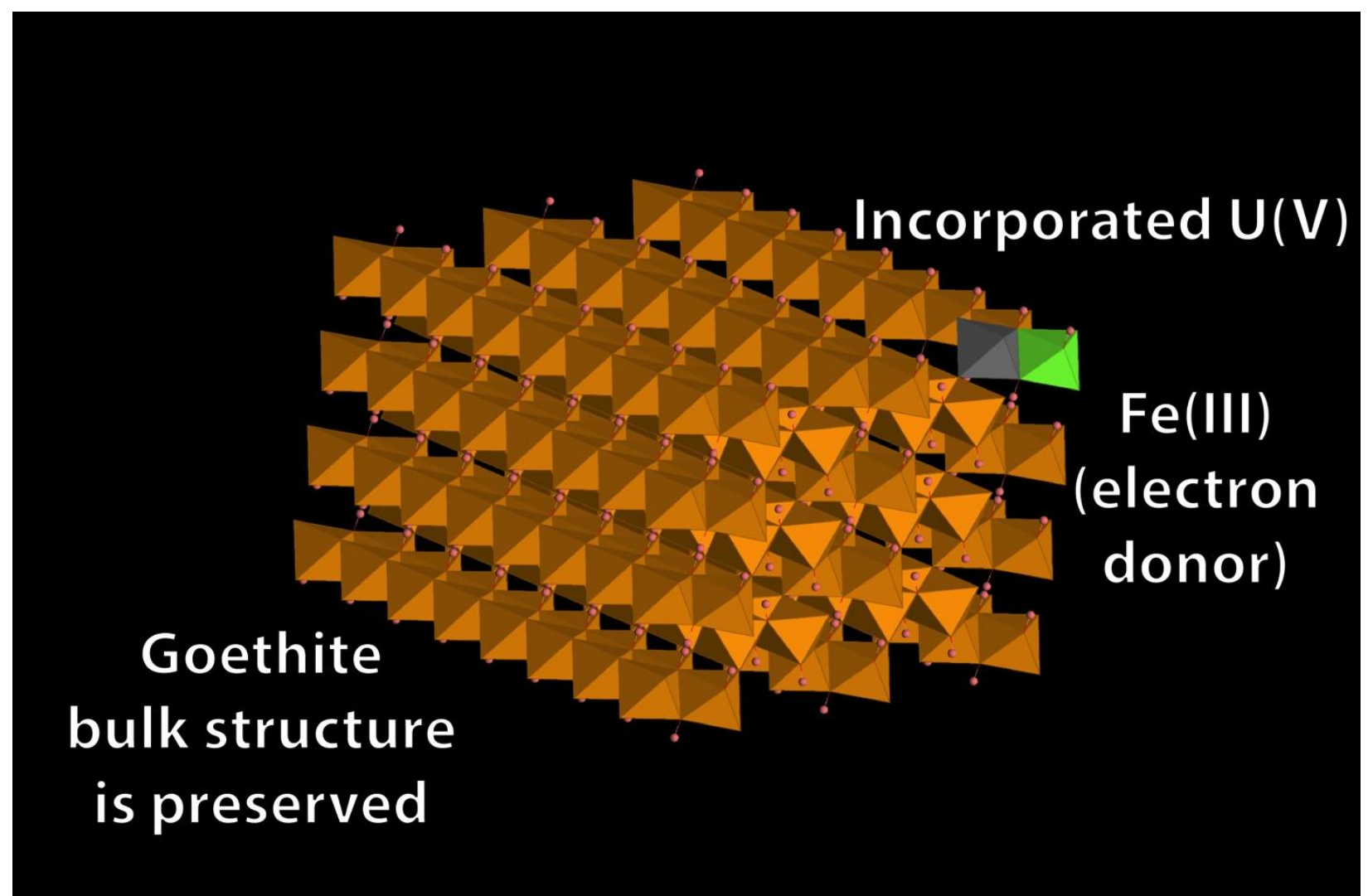

Figure 15. The final product of the $U$ incorporation process is a U(V) atom in octahedral coordination, with the Fe atom that was its electron donor positioned toward the exterior of the incorporated U. Local charge balance is achieved by protonation/de-protonation and/or the introduction of Fe(III) vacancies, but the bulk goethite structure is preserved. Uranium is grey, $\mathrm{Fe}$ (III) in the iron oxide is yellow, and Fe(II/III) participating in the reaction is shown in green. 